\title{
Hydrogen: A Novel Option in Human Disease Treatment
}

\author{
Mengling Yang $\mathbb{D}^{1}{ }^{1}$ Yinmiao Dong $\mathbb{D}^{1},{ }^{1}$ Qingnan He $\mathbb{D}^{1},{ }^{1}$ Ping Zhu $\mathbb{D}^{2},{ }^{2}$ Quan Zhuang $\mathbb{D},{ }^{3}$ \\ Jie Shen $\left(1,{ }^{1}\right.$ Xueyan Zhang $\left({ }^{4},{ }^{4}\right.$ and Mingyi Zhao $\oplus^{1}$ \\ ${ }^{1}$ Department of Pediatrics, The Third Xiangya Hospital, Central South University, Hunan Province, Changsha 410013, China \\ ${ }^{2}$ Guangdong Cardiovascular Institute, Guangdong Provincial People's Hospital, Guangdong Academy of Medical Sciences, \\ Guangzhou, Guangdong 510100, China \\ ${ }^{3}$ Transplantation Center of the 3rd Xiangya Hospital, Central South University, Hunan Province, Changsha 410013, China \\ ${ }^{4}$ Xiangya School of Medicine, Central South University, Hunan Province, Changsha 410013, China
}

Correspondence should be addressed to Mingyi Zhao; 36163773@qq.com

Received 21 March 2020; Revised 6 June 2020; Accepted 13 July 2020; Published 8 September 2020

Academic Editor: Luciano Saso

Copyright (C) 2020 Mengling Yang et al. This is an open access article distributed under the Creative Commons Attribution License, which permits unrestricted use, distribution, and reproduction in any medium, provided the original work is properly cited.

$\mathrm{H}_{2}$ has shown anti-inflammatory and antioxidant ability in many clinical trials, and its application is recommended in the latest Chinese novel coronavirus pneumonia (NCP) treatment guidelines. Clinical experiments have revealed the surprising finding that $\mathrm{H}_{2}$ gas may protect the lungs and extrapulmonary organs from pathological stimuli in NCP patients. The potential mechanisms underlying the action of $\mathrm{H}_{2}$ gas are not clear. $\mathrm{H}_{2}$ gas may regulate the anti-inflammatory and antioxidant activity, mitochondrial energy metabolism, endoplasmic reticulum stress, the immune system, and cell death (apoptosis, autophagy, pyroptosis, ferroptosis, and circadian clock, among others) and has therapeutic potential for many systemic diseases. This paper reviews the basic research and the latest clinical applications of $\mathrm{H}_{2}$ gas in multiorgan system diseases to establish strategies for the clinical treatment for various diseases.

\section{Introduction}

Molecular hydrogen $\left(\mathrm{H}_{2}\right)$ is the lightest chemical element in the earth's atmosphere. $\mathrm{H}_{2}$ is often mixed in gas cylinders for deep-sea divers to breathe, to prevent decompression and nitrogen sickness [1]. In mammals, $\mathrm{H}_{2}$ is spontaneously produced by intestinal bacteria in the process of anaerobic metabolism to produce energy and is enzymatically catabolized by hydrogenases to provide electrons.

Therapeutic applications of $\mathrm{H}_{2}$ were first described in 1975. Dole et al. reported that hyperbaric hydrogen caused marked regression of tumors in mice with skin squamous carcinoma [2]. However, hyperbaric $\mathrm{H}_{2}$ is not a clinically feasible option, and $\mathrm{H}_{2}$ is a physiologically inert gas that seems not to react with any active substances, including oxygen gas, in mammalian cells. Thus, $\mathrm{H}_{2}$ was perceived as being nonfunctional and was disregarded clinically.
In 2007, the potential therapeutic benefits of $\mathrm{H}_{2}$ were described. Ohsawa et al. discovered that $\mathrm{H}_{2}$ has selective antioxidant properties that protect the brain against ischemia/reperfusion (I/R) injury and stroke by specifically neutralizing hydroxyl radicals $(\mathrm{OH})$ and peroxynitrite (ONOO-) but not superoxide anion radical $\left(\mathrm{O}_{2^{-}}\right)$, hydrogen peroxide $\left(\mathrm{H}_{2} \mathrm{O}_{2}\right)$, and nitric oxide (NO) [3]. The report generated worldwide attention and thrust $\mathrm{H}_{2}$ into the spotlight of therapeutic medical gas research. Many studies using cellular, animal, and clinical experiments in a variety of biomedical fields have explored the therapeutic and preventive effects of $\mathrm{H}_{2}$. The collective data have indicated that $\mathrm{H}_{2}$ is an important pathophysiological regulatory factor with antioxidative, anti-inflammatory, and antiapoptotic effects on cells and organs [4-6]. It is so convenient to use that $\mathrm{H}_{2}$ can be easily administered in various ways, including inhalation, injection of $\mathrm{H}_{2}$-rich saline (HRS), drinking $\mathrm{H}_{2}$-rich 


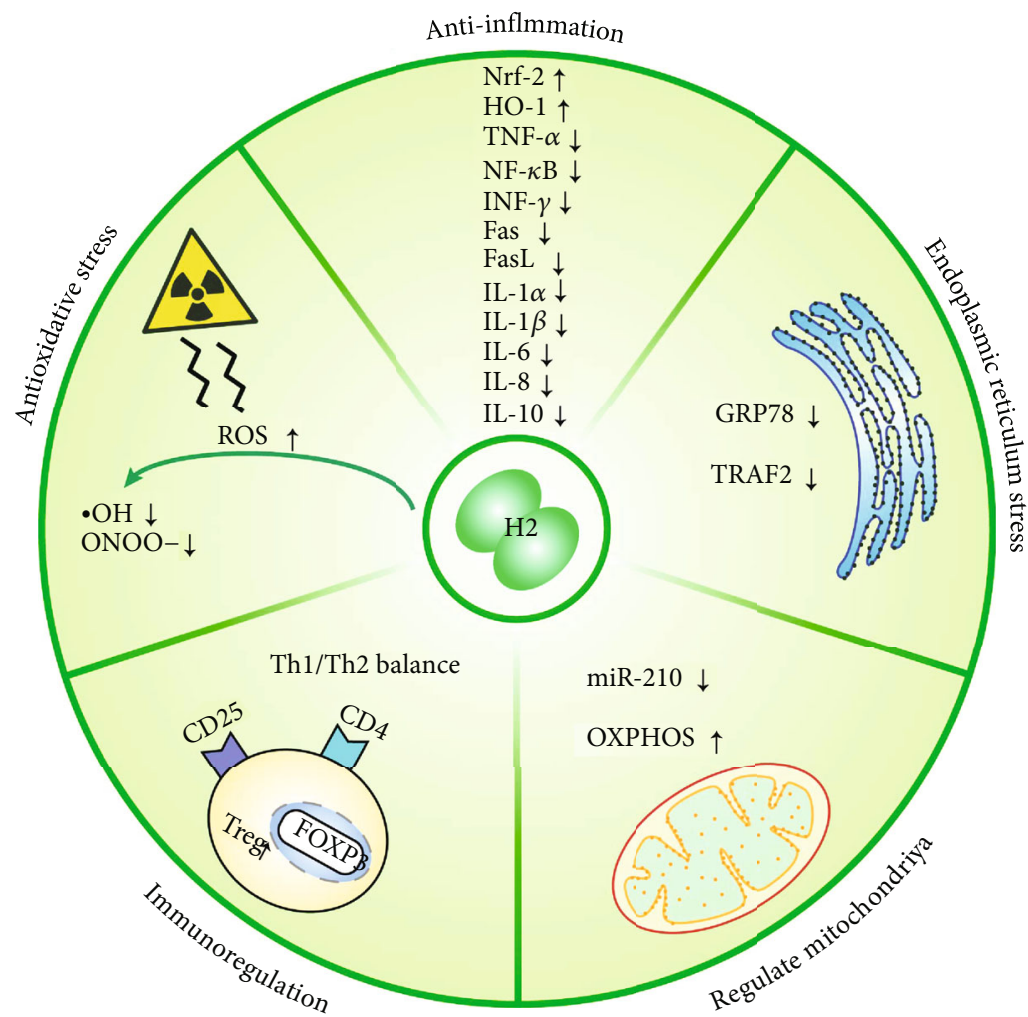

FIgure 1: Biological effects of $\mathrm{H}_{2} \cdot \mathrm{H}_{2}$ exhibits selective antioxidative and anti-inflammatory activities and can regulate ER stress, mitochondria, and immune function. $\mathrm{H}_{2}$ selectively scavenges $\mathrm{OH}$ and ONOO-, upregulates Nrf- 2 and $\mathrm{HO}-1$, and downregulates the expression of proinflammatory and inflammatory cytokines that include TNF- $\alpha$, NF- $\kappa$ B, INF- $\gamma$, Fas, FasL, IL- $1 \alpha$, IL- $1 \beta$, IL-6, IL-8, and IL10, as well as downregulates ER stress-related factors that include GRP78 and TRAF2. $\mathrm{H}_{2}$ also reduces miR-210 and activates OXPHOS in mitochondria. Finally, $\mathrm{H}_{2}$ increases $\mathrm{CD} 4+\mathrm{CD} 25+\mathrm{Foxp} 3+$ Treg cells and maintains the Th1/Th2 balance.

water (HW), bathing in HW, and using HRS eyedrops. As well, the production of intestinal $\mathrm{H}_{2}$ by bacteria can be increased via oral administration of acarbose and lactulose. Liu and his colleagues demonstrated that the hydrogen concentration reached a peak of $5 \mathrm{~min}$ after oral and intraperitoneal administration, and in only $1 \mathrm{~min}$ following intravenous administration [7].

Beginning on 31 December 2019 in Wuhan, China, illness and pneumonia named coronavirus disease-2019 (COVID-19) caused by severe acute respiratory syndrome coronavirus 2 (SARS-CoV-2) has spread to become a pandemic. The seventh edition of Chinese Clinical Guidance for COVID-19 Pneumonia Diagnosis and Treatment ( $7^{\text {th }}$ edition) issued by China National Health Commission recommended the inhalation of oxygen mixed with hydrogen gas $\left(33.3 \% \mathrm{O}_{2}\right.$ and $66.6 \% \mathrm{H}_{2}$ ), bringing $\mathrm{H}_{2}$ to the forefront of contemporary therapeutic medical gas research.

The preventive and therapeutic effects of $\mathrm{H}_{2}$ have been intensively investigated for various pathological processes. In this review, we summarize the most recently published literature concerning the use of $\mathrm{H}_{2}$ in respiratory, cardiovascular, nervous, digestive, reproductive, urinary, motor, and sensory system diseases, as well as for the treatment of metabolic syndrome and cancer. We also briefly discuss some known mechanisms underlying the action of $\mathrm{H}_{2}$. We hope that this information will increase the understanding of the therapeutic activities of $\mathrm{H}_{2}$ and inform future $\mathrm{H}_{2}$-based therapies.

\section{Mechanisms of the Action of $\mathbf{H}_{2}$}

To fully explain the preventive and therapeutic effects of $\mathrm{H}_{2}$, biological effects and possible mechanisms are summarized in Figures 1 and 2.

2.1. Anti-Inflammatory Effect of $\mathrm{H}_{2}$. The anti-inflammatory effect of $\mathrm{H}_{2}$ has already been reported in many studies. In the early stage of inflammation, $\mathrm{H}_{2}$ can reduce the infiltration of neutrophils and M1 macrophages, and the release of proinflammatory factors by downregulating the expression of intercellular cell adhesion molecule-1 (ICAM-1), granulocyte-macrophage colony-stimulating factor (GMCSF), and granulocyte colony-stimulating factor (G-CSF) [4] $\mathrm{H}_{2}$ can also inhibit the expression of proinflammatory cytokines during the progress of inflammation and has been revealed in many animal models to decrease the overexpression of early proinflammatory cytokines, such as interleukin(IL-) $1 \beta$, IL-6, IL-8, IL-10, tumor necrosis factor-alpha (TNF$\alpha$ ) [8], interferon-gamma (INF- $\gamma$ ), and late proinflammatory cytokines, such as high-mobility group box-1 protein (HMGB1) [9]. Tanaka and colleagues [10] conducted a gene array analysis of lung grafts from donor rats pretreated with hydrogen ventilation. The authors described that pretreatment with $\mathrm{H}_{2}$ obviously elevated the expression of two stress-response proteins: heat shock protein A5 (HSPA5) and dual-specificity phosphatase 1 (DUSP1). HSP70 protein 


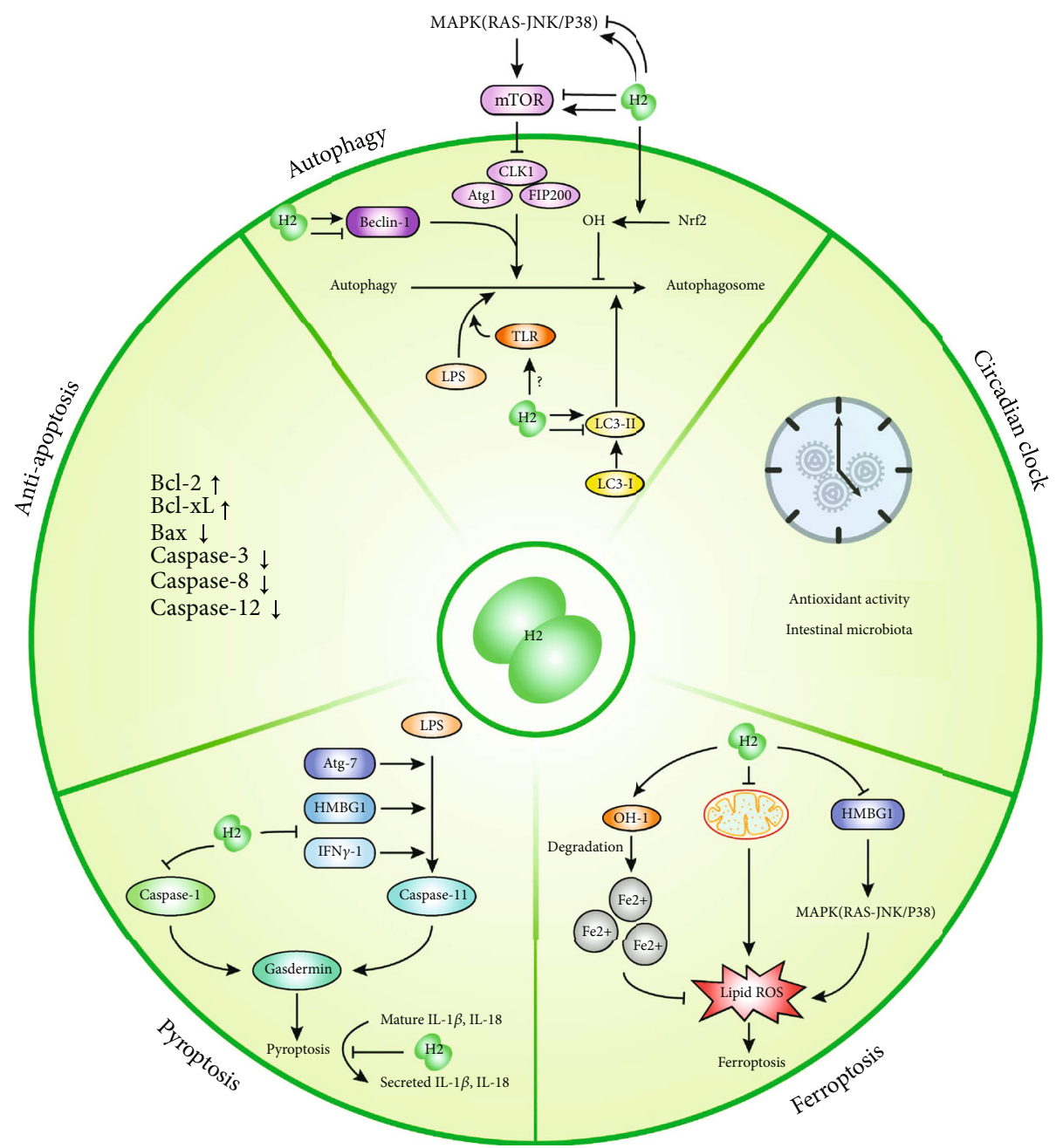

FIGURE 2: Various effects of $\mathrm{H}_{2}$ on cell death. Activities of $\mathrm{H}_{2}$ include inhibition of apoptosis, and the regulation of autophagy, circadian clock, ferroptosis, and pyroptosis.

encoded by HSPA5 has anti-inflammatory and antiapoptotic properties. DUSP1 can suppress excessive autophagy by inactivating mitogen-activated protein kinases (MAPKs) to alleviate the inflammatory response. Therefore, we speculate that $\mathrm{H}_{2}$ can positively regulate the expression of stressresponse proteins and improve the anti-inflammatory ability of the organs. Another study [11] demonstrated ventilation with $2 \% \mathrm{H}_{2}$ in the air significantly reduced the mRNA levels of the early growth responsive gene-1 (Egr-1) and chemokine (C-C motif) ligand 2 (CCL2), suggesting that $\mathrm{H}_{2}$ can affect the progress of inflammation by regulating the transcription of proinflammatory regulatory factors and chemokines. In many diseases, such as airway inflammation and cerebral ischemia, type I hypersensitivity caused by mast cell activation will aggravate the tissue congestion and edema $[12,13] . \mathrm{H}_{2}$ inhibits the body's inflammatory response by inhibiting Th2 reaction to reduce mast cell activation as well [14]. $\mathrm{H}_{2}$ can also regulate inflammation by regulating the physiological pathway of $\mathrm{T}$ cells. For example, hydrogen treatment can inhibit the overactivation of the immune system by restoring the loss of regulatory $\mathrm{T}$ cells (Tregs) [15] and alleviates inflammation by preventing activation-regulated chemokine-mediated T-cell chemotaxis. The regulation effects of $\mathrm{H}_{2}$ on programmed cell death, oxidative stress, and mitochondrial function are closely related to the inflammatory response. However, the antiinflammatory effect of hydrogen cannot be overstated. It would be better to be used as a supplementary therapy.

2.2. Regulation of Oxidative Stress. Many studies have established the antioxidant activity of $\mathrm{H}_{2}$. However, recently, a study [16] has shown that hydrogen can rapidly and slightly increase 8-hydroxy-2'-deoxyguanosine (8-OHdG) in urine, a marker for oxidative stress, to a similar level as the increase caused by exercise. Exercise-induced generation of reactive oxygen species (ROS) is crucial in cell adaptation, and short-term exposure to low levels of ROS can protect neurons from oxidative stress that would otherwise be lethal [5]. $\mathrm{H}_{2}$ may act as a mitohormetic effector to mediate the beneficial effects on the body through hormetic mechanisms [16].

The antioxidant effect of $\mathrm{H}_{2}$ is mainly reflected in several aspects. $\mathrm{H}_{2}$ was first found to directly eliminate hydroxyl radicals and peroxynitrite. Compared with traditional antioxidants, such as superoxide dismutase (SOD), catalase, 
and $\alpha$-tocopherol, $\mathrm{H}_{2}$ can easily penetrate biofilms and does not affect the normal metabolic redox reaction due to its small molecular weight and antioxidative activity which selectively affects only the strongest oxidant [17]. $\mathrm{H}_{2}$ can enhance the expression of the heme oxygenase-1 (HO-1) antioxidant by activating nuclear factor erythroid 2-related factor 2 (Nrf-2), an upstream regulating molecule of HO- 1. $\mathrm{H}_{2}$ can also downregulate ROS directly or as a regulator of a gas-mediated signal. Further, by upregulating the expression of SOD and glutathione (GSH), and downregulating the expression of NADPH oxidase (NOX2) [18], $\mathrm{H}_{2}$ can significantly reduce ROS. Another study [19] showed that $\mathrm{H}_{2}$ mainly blocks the phosphorylation of ASK1 and its downstream signal molecules p38 MAPK or c-Jun N-terminal kinase (JNK), but not the production of ROS by NADPH oxidase.

The effects on the free radical chain reaction of lipid peroxidation may be another important mechanism of hydrogen antioxidation. Since Otha et al. reported at the 5th Symposium of Medical Molecular Hydrogen at Nagoya, Japan, in 2015 that exposure to a low concentration of hydrogen causes abnormal oxidation of phospholipids [20], many studies have established that $\mathrm{H}_{2}$ can protect cells from lipid and fatty acid peroxidation $[21,22]$. Additionally, $\mathrm{H}_{2}$ can also reduce the expression of myeloperoxidase (MPO) [23] or decrease mitochondrial oxidoreductase activity [21] and stabilize mitochondrial membrane potential [24], so as to improve the tissue damage caused by oxidative stress.

2.3. Regulation of Endoplasmic Reticulum Stress. The accumulation of unfolded protein in the endoplasmic reticulum (ER) caused by pathological stress can trigger ER stress. Zhao et al. [18] observed that hydrogen inhalation significantly reduced the ER stress-related protein and alleviated tissue damage in myocardial I/R injury and later found that a mixture of $\mathrm{H}_{2}$ and $\mathrm{O}_{2}$ can block endoplasmic reticulum stress via the PKR-like ER-localized eIF2 $\alpha$ kinase-eukaryotic initiation factor 2 alpha-activating transcription factor 4 (PERK-eIF2 $\alpha$ ATF 4), inositol-requiring enzyme 1-X-box binding protein 1 (IRE 1-XBP1), and ATF 6 pathways. A study of the relationship between $\mathrm{H}_{2}$ and ER stress in rats with I/R injury found that $\mathrm{H}_{2}$ induced the decrease of GRP78 and TNF receptorassociated factor 2 (TRAF2) expression [25], suggesting that the protective effects of $\mathrm{H}_{2}$ on myocardial I/R injury are related to decreased ER stress.

2.4. Regulation of Mitochondria. The accumulation of ROS can trigger the release of calcium from the ER, which results in the depolarization of mitochondria and the loss of the mitochondrial membrane potential [26]. The negative regulation of ROS and the inhibition of programmed cell death by $\mathrm{H}_{2}$ help maintain the structure and function of mitochondria. It was reported [27] that hydrogen treatment can block the opening of mitochondrial permeability transition pores in neurons during neurodegenerative disease. However, whether $\mathrm{H}_{2}$ can indirectly block these pores by reducing the production of ROS or acts directly is unclear. Early studies [28] showed that HRS moderated mitochondrial structural damage and simultaneously reduced microRNA- (miR-)
210 in hypoxic-reperfusion nerve tissue. However, recent studies have shown that the increase of miR-210 in injured tissues may be a compensatory action to maintain cell function and reduce ROS production $[29,30]$. Whether $\mathrm{H}_{2}$ can directly inhibit miR- 210 or indirectly reduce it by alleviating inflammation also remains unclear.

Mitochondrial damage caused by oxidative stress is an important cause of many neurodegenerative diseases. Early clinical experiments on Parkinson's disease [31] showed that $\mathrm{H}_{2}$ can significantly improve neurodegenerative symptoms with a therapeutic effect comparable to that of nonergot dopamine therapy. This cannot be explained by the antioxidative effect of $\mathrm{H}_{2}$, and thus, it was suggested that $\mathrm{H}_{2}$ may target mitochondria to improve the energy metabolism of cells. The observation that $\mathrm{H}_{2}$ treatment significantly improved the level of SH-SY5Y ATP and $\Delta \psi \mathrm{m}$ in neuroblastoma [32] is an indication that $\mathrm{H}_{2}$ treatment can elevate energy metabolism in mitochondria by activating oxidative phosphorylation.

The observations of the conserved structural features shared between hydrogenases and the energy-converting complex I prompted the suggestion that $\mathrm{H}_{2}$ might serve as both a reductant and oxidant [24]. The hypothetical function of $\mathrm{H}_{2}$ in rectifying mitochondrial electron flow can explain the scavenging effect on ROS and the ability to slightly improve oxidative stress.

2.5. The Effects of Hydrogen on the Immune System. The main effect of $\mathrm{H}_{2}$ on the immune system is to reduce the production of immune active substances. Evidence suggests that $\mathrm{H}_{2}$ relieves inflammation in some autoimmune disorders, including rheumatoid arthritis (RA) [33,34], dermatomyositis [35], and psoriasis [36]. However, whether $\mathrm{H}_{2}$ directly influences immune cells or organs remains unclear. Recent studies have found that $\mathrm{H}_{2}$ can relieve the dysregulated Th1/Th2 balance and can influence the number of $\mathrm{T}$ regulatory cells (Tregs). $\mathrm{H}_{2}$ was first reported to restore Treg loss in a rat model of chronic pancreatitis [15] and was later proven to increase $\mathrm{CD} 4+\mathrm{CD} 25+$ Foxp $3+$ Treg cells and significantly reduce nasal mucosa damage in animals with allergic rhinitis, which may be secondary to the restoration of Th1/Th2 balance [37]. Upregulation of Tregs has been reported in cerebral I/R models [28]. This may be caused by the upregulation of tumor necrosis factor-beta 1 (TNF$\beta 1$ ) and downregulation of miR-21 or miR-210. $\mathrm{H}_{2}$ can also activate peroxisome proliferator-activated receptor-gamma coactivator-1 alpha (PGC-1 $\alpha$ ) to influence some kinds of T cells [38]. The specific mechanisms underlying the effects of $\mathrm{H}_{2}$ on immune cells remain to be defined.

\subsection{Effects of $\mathrm{H}_{2}$ on Cell Death}

2.6.1. Prevention of Apoptosis. Apoptosis is a form of programmed cell death characterized by cell shrinkage, apoptotic body formation, karyorrhexis, and chromatin condensation. Apoptosis can be induced by both intrinsic and extrinsic signals. $\mathrm{H}_{2}$ exhibits antiapoptotic effects by up- or downregulating apoptosis-related factors. $\mathrm{H}_{2}$ inhibits the expression of the proapoptotic factors B-cell lymphoma-2-associated $\mathrm{X}$-protein (Bax), caspase-3, caspase-8, and caspase-12 and 
upregulates the antiapoptotic factors B-cell lymphoma-2 (Bcl-2) and B-cell lymphoma-extra-large (Bcl-xl) [6]. Additionally, Terasaki and colleagues reported that $\mathrm{H}_{2}$ can downregulate the gene expression of proapoptotic $\mathrm{Bax}$ and inhibit its translocation to mitochondria by an unknown mechanism [39]. $\mathrm{H}_{2}$ can also inhibit apoptosis by activating the phosphatidylinositol-3-kinase/protein kinase B (PI3K/AKT) and the Janus kinase 2/signal transducer and activator of transcription 3 (JAK2-STAT3) signaling pathways in rats with myocardial ischemia-reperfusion injury (MIRI) [40, 41], as well as downregulating the p38 MAPK signaling pathway in rat models with lipopolysaccharide- (LPS-) induced acute lung dysfunction [42] and cerebral ischemia-reperfusion injury (CIRI) [43]. Interestingly, Wang et al. recently discovered that $\mathrm{H}_{2}$ inhibited the growth, migration, and invasion of the A549 and H1975 lung cancer cell lines and promoted cell apoptosis, suggesting that $\mathrm{H}_{2}$ might play crucial roles in the treatment of lung cancer [44]. Li et al. also revealed the apoptosis-inducing effect of $\mathrm{H}_{2}$ on KYSE-70 human esophageal squamous cell carcinoma cells [45]. Thus, $\mathrm{H}_{2}$ may protect normal cells from damage and suppressing cancer cells.

2.6.2. Autophagy. Although the activation of autophagy can maintain the energy balance of cells through the degradation of macromolecular substances, excessive autophagy or autophagy-related stress triggered by stress stimuli will aggravate the inflammatory damage in tissues and organs. $\mathrm{H}_{2}$ plays a dual role in the regulation of autophagy. Under the regulation of $\mathrm{H}_{2}$, autophagy can be activated when protein aggregation becomes toxic and blocked once excessive autophagy causes damage to tissues. Zhuang et al. [46] showed that $\mathrm{H}_{2}$ treatment downregulated the expression of phosphomammalian target of rapamycin (p-mTOR)/mTOR and p62 in LPS-treated neuroglial cells and increased the expression of phospho-AMP-activated protein kinase ( $\mathrm{p}$ AMPK)/AMPK, light chain 3 (LC3) II/LC3 I, triggering receptor expressed on myeloid cells 2 (TREM-2), and Beclin-1 to activate autophagy and attenuate neuroinflammation in sepsis. Guan et al. [47] revealed that $\mathrm{H}_{2}$ can ameliorate chronic intermittent hypoxia-induced kidney injury by decreasing ER stress and inducing autophagy by inactivating oxidative stress-dependent $\mathrm{p} 38$ and JNK MAPKs. $\mathrm{H}_{2}$ can also inhibit autophagy by downregulating NF- $\kappa \mathrm{B}$, Beclin-1, and MAPK and upregulating the HO-1, mTOR, and LC3B signaling pathways. Zhang et al. [42] found that saturated hydrogen saline alleviated LPS-treated lung injury and significantly reduced the expression of autophagy-related proteins, including LC3 and Beclin-1 $(P<0.05)$, suggesting that hydrogen saline can protect lung tissue against excessive autophagy. Saturated hydrogen saline can prevent excessive autophagy by eliminating excessive free radicals, reducing the concentration of free radicals in lung tissue, and promoting the expression of mTOR. HO-1 can function as an endogenous cytoprotective protein to assist in the prevention of oxidative stress and excessive cell autophagy. $\mathrm{H}_{2}$ can increase the tissue expression of $\mathrm{HO}-1$ by promoting the expression of nuclear erythroid 2-related factor 2 (Nrf2) [48].

Toll-like receptors (TLRs) could be a potential target for $\mathrm{H}_{2}$ in autophagy regulation. TLR4, a key factor in the recog- nition of viral and bacterial factors, can be activated by LPS to induce autophagy of macrophages [49]. The inhibition of an LPS-induced inflammatory response by $\mathrm{H}_{2}$ supports the speculation that TLR may be a potential pathway of hydrogen-induced autophagy.

2.6.3. Pyroptosis. Pyroptosis is an inflammatory programmed cell death pathway that protects multicellular hosts from invasive pathogens, including microbial infections [50]. Human and mouse caspase-1, human caspase- 4 and caspase-5, and mouse caspase- 11 act as essential activators of pyroptosis. While pyroptosis is normally beneficial for the host, excessive pyroptosis can result in sepsis and septic shock. Although there is no experimental data to explain the relationship between $\mathrm{H}_{2}$ and the pyroptosis pathway, it is conceivable that the regulation of some inflammatory factors and nuclear factors by $\mathrm{H}_{2}$ will interfere with the triggering of pyroptosis, or at least reduce pyroptosis-related inflammation. In one study [51], inhalation of $2 \% \mathrm{H}_{2}$ reduced the expression of caspase-1, a key factor for pyroptosis activation. Physical rupture of cells caused by pyroptosis leads to the release of the proinflammatory cytokines IL- $1 \beta$ and IL-18, while hydrogen pretreatment can significantly reduce the level of these cytokines [52]. $\mathrm{H}_{2}$ has also been shown to regulate the expression of Atg7, which inhibits pyroptosis [53]. It has been proposed that HMGB1 [54] and IFN- $\gamma$ [50] are necessary for caspase-11-dependent pyroptosis activation. The negative effect of $\mathrm{H}_{2}$ on the expression of these two factors may protect cells from pyroptosis. $\mathrm{H}_{2}$ is able to block the expression of caspase-3 [55], which serves both as the activator of apoptosis, and also blocks pyroptosis by cleaving gasdermin D [56]. Bidirectional crosstalk exists between the caspase- 3 produced in apoptosis and the caspase in pyroptosis. The mechanism of this crosstalk remains unclear.

Human immunodeficiency virus (HIV) can accelerate the depletion of $\mathrm{CD} 4+\mathrm{T}$ cells via interferon-gamma inducible protein 16- (IFI16-) triggered pyroptosis [50]. Thus, the regulation of pyroptosis by $\mathrm{H}_{2}$ may be a potential mechanism to treat HIV affection.

2.6.4. Ferroptosis. Ferroptosis is a form of regulated cell death proposed by Dixon et al. [57] in 2012. Ferroptosis is accompanied by a lethal iron-dependent accumulation of lipid hydroperoxides. Although laboratory verification has not been forthcoming, we can still speculate that hydrogen can interfere with ferroptosis to alleviate inflammatory necrosis of tissues and organs in the pathological state, given the great deal of overlap between hydrogen regulation and ferroptosis pathways. It has been well-established that hydrogen has a negative regulatory effect on ROS. We speculate that the most critical redox imbalance in the process of ferroptosis will be eliminated by hydrogen; thus, ferroptosis will be blocked. In addition, $\mathrm{H}_{2}$ is able to block MAPK pathways, which are to prevent the depletion of reducing substances caused by iron ions and ROS [58]. A recent study [59] showed that HMGB1, which can be downregulated by hydrogen [9], can act as a positive regulator of ferroptosis via the RAS-JNK/p38 pathway. 
$\mathrm{HO}-1$ activity can be increased by hydrogen. $\mathrm{HO}-1$ is a potential source of intracellular iron, and a recent study [60] demonstrated that HO-1-deficient renal epithelial cells were more sensitive to ferroptosis, indicating that free iron produced by HO-1 does not promote ferroptosis itself, and that HO-1 has an antiferroptotic effect. However, the effects of hydrogen on ferroptosis may not always be inhibitory. For example, miR-9, an inflammatory miRNA that is downregulated by hydrogen, can reduce the occurrence of ferroptosis [16]. The mechanism underlying the action of hydrogen on ferroptosis is yet to be fully clarified.

Some of the anti-inflammatory and antioxidation mechanisms of hydrogen are similar to those of GPX4 [61]. Both molecules have negative effects on the formation of lipid peroxide and NF- $\kappa$ B. The combination of hydrogen and GPX4 activator may provide a new solution for the treatment of inflammation and other lipid peroxidationmediated diseases.

2.6.5. Circadian Clock. The circadian clock refers to an endogenous oscillator that controls $24 \mathrm{~h}$ physiological, metabolic, and behavioral processes. This clock is particularly crucial in maintaining homeostasis [62]. Intestinal microbiota, which regularly produce hydrogen gas in the process of the energy-producing anaerobic fermentation [63], undergo diurnal oscillations in composition and function [64]. In humans, the amount of hydrogen produced varies depending on the individual and the time of the day. Wilking et al. suggested that the circadian regulation of protein expression plays an important role in the cellular response to oxidative stress; they concluded that levels of byproducts of oxidative stress, such as protein damage, or lipid peroxidation, also oscillate with circadian rhythmicity, indicating circadian oscillations of oxidative stress responses. Thus, this rhythmicity of antioxidant levels can be exploited for a more precise targeting of ROS to offer better protection for the cells [65]. As the antioxidant activity of $\mathrm{H} 2$ has been widely verified, we suggest that $\mathrm{H} 2$ may exert a negative regulatory effect on ROS by regulating circadian rhythm, but there is yet no evidence regarding how $\mathrm{H} 2$ is involved in the regulation of circadian rhythm.

\section{Preventive and Therapeutic Applications of $\mathbf{H}_{2}$}

$\mathrm{H}_{2}$ has preventive and therapeutic effects on different system diseases (Table 1).

3.1. Effects of Hydrogen on the Respiratory System. The seventh edition of Chinese Clinical Guidance for COVID-19 Pneumonia Diagnosis and Treatment ( $7^{\text {th }}$ edition) issued by China National Health Commission recommends the inhalation of $\mathrm{O}_{2}$ mixed with $\mathrm{H}_{2}$. The recommendation recognized the efficacy of hydrogen in the treatment of respiratory diseases. A recent review summarized several researches on SARS-CoV-2 and pointed out that the possibility that $\mathrm{H}_{2}$ could alleviated SARS-CoV-2 infection though affecting cellular responses [66]. Antiviral efficacy and safety of $\mathrm{H} 2$ in treating NCP patients have attracted the attention of researchers in completed or ongoing multicenter clinical trials. Guan et al. [67] evidenced that inhalation of $\mathrm{H}_{2} / \mathrm{O}_{2}$ mixed gas efficiently improved respiratory symptoms especially dyspnea as well as disease severity without observed side effects. Another multi-centre RTC (ChiCTR2000030258) aims verifying the efficacy and safety of $\mathrm{H}_{2} / \mathrm{O}_{2}$ mixed gas is ongoing. Due to its small molecular weight, hydrogen in the inhaled gas mixture can reduce airway resistance, increase oxygen dispersion, and increase oxygen flow. COVID-19 can provoke an inflammatory storm by excessively activating the immune system, causing severe inflammatory damage to the lungs and extrapulmonary tissue, which is also the main cause of death [68].

A study involving 41 patients with NCP showed that patients in the intensive care unit displayed a significantly higher level of inflammatory factors that included IL-2, IL-7, IL-10, and TNF- $\alpha$ and that most of these factors could be downregulated by hydrogen [69]. We speculate that the application of hydrogen may reduce the risk of inflammatory storm and thus prevent severe effects. Many NCP patients need ventilator-assisted therapy. Inflammatory changes in the respiratory system make lung tissue prone to ventilatorinduced lung injury (VILI), even with low tidal volume [70]. Ventilation with $2 \% \mathrm{H}_{2}$ was proved to be able to downregulate the mRNAs for proinflammatory mediators such as TNF- $\alpha$, IL- $1 \beta$, Egr-1, and CCL2 and induced antiapoptotic genes including Bcl-2 and $\mathrm{Bcl}-\mathrm{xL}$. It is consistent with the histopathological results which showed that inflammatory cell infiltration and bronchial epithelial apoptosis were improved in VILI mice after $\mathrm{H}_{2}$ treatment. $\mathrm{H}_{2}$ has a potential to protect human lung tissues from VILI as well via its anti-inflammatory, antioxidant, and antiapoptotic effects [11]. Moreover, hydrogen can also increase surfactant proteins to prevent further lung injury [11]. One study reported that chest computed tomography scans performed at the early stage in patients that ultimately developed in severe infection revealed multiple small flake shadows and interstitial changes, suggesting that pulmonary fibrosis affects the prognosis of the disease. HRS has been reported to reverse epithelial-mesenchymal transition (EMT) and prevent pulmonary fibrosis by inhibiting oxidative stress and increasing the expression of E-cadherin [71].

Hydrogen also has the potential to protect lung tissues from pulmonary hypertension [72], sepsis [73], smoke inhalation injury [74], hemorrhagic shock and resuscitation [75], and other toxic substances/events. In animal models, hydrogen also affects asthma and chronic obstructive pulmonary disease [76].

3.2. Effects of Hydrogen on the Nervous System. Myriad forms of irreversible damage that occur in nervous system diseases are often caused by neuroinflammation, excessive oxidative stress, mitochondrial dysfunction, and cell death. The therapeutic effects of hydrogen on the nervous system have been verified in animal models and clinical trials. Hydrogen can reportedly reduce the loss of dopaminergic neurons and can improve nigrostriatal degeneration a mouse model of Parkinson's disease (PD) following treatment with 6-hydroxydopamine [77] and 1methyl-4-phenyl-1,2,3,6-tetrahydropyridine [78]. A recent 
TABle 1: Mechanisms of $\mathrm{H}_{2}$ in multiple systemic diseases.

\begin{tabular}{|c|c|c|}
\hline Diseases & Effects of $\mathrm{H}_{2}$ & Reference \\
\hline \multirow{3}{*}{ Respiratory system } & Regulates IL-2, IL-7, IL-10, and TNF- $\alpha$ & {$[66]$} \\
\hline & Increases surfactant proteins & [11] \\
\hline & Reverses EMT and increases E-cadherin & [68] \\
\hline \multirow{3}{*}{ Cardiovascular system } & Suppresses macrophage infiltration, TNF- $\alpha$ expression, and vascular aging & {$[88]$} \\
\hline & Inhibits cardiomyocyte apoptosis & {$[39,40]$} \\
\hline & Decreases MDA, 8-OHdG, and IL-1 $\beta$ & {$[92,93]$} \\
\hline \multirow{2}{*}{ Nervous system } & Reduces loss of dopaminergic neurons and improves nigrostriatal degeneration & {$[74,75]$} \\
\hline & Reduces neurological deficits and endothelial cell injury & {$[83,84]$} \\
\hline \multirow{3}{*}{ Digestive system } & Induces HO-1 and Sirt1 expression & [98] \\
\hline & Activates the A2A receptor-mediated PI3K-Akt pathway & [99] \\
\hline & Inhibits bile acid oxidation & [114] \\
\hline \multirow{3}{*}{ Reproductive system } & Inhibits cell proliferation and improves SOD & {$[130]$} \\
\hline & Improves serum levels of anti-Müllerian hormone & [133] \\
\hline & Improves serum testosterone level & [135] \\
\hline \multirow{3}{*}{ Urinary system } & Increases Il- 4 and Il-13 and promotes macrophage polarization to the M2 type & [140] \\
\hline & Activates the Keap1/Nrf2 signaling pathway & [145] \\
\hline & Prevents HK-2 cells from undergoing EMT & \\
\hline \multirow{2}{*}{ Motor system } & Reduces blood lactate levels & {$[47]$} \\
\hline & Suppresses serum 8-OHdG levels & {$[154]$} \\
\hline \multirow{2}{*}{ Sensory system } & Reduces wound area and levels of proinflammatory cytokines & {$[159]$} \\
\hline & Improves auditory brainstem response & {$[161]$} \\
\hline \multirow{3}{*}{ Metabolic syndrome } & Decreases LDL and increases high-density lipoprotein & [148] \\
\hline & Decreases glucose and insulin levels & [149] \\
\hline & Stimulates energy metabolism & {$[152]$} \\
\hline \multirow{2}{*}{ Cancer } & Controls cancer progression and improves quality-of-life & {$[140]$} \\
\hline & Reduces proportion of terminal PD-1+ CD8+ T cells & {$[37]$} \\
\hline
\end{tabular}

clinical trial showed that HW can improve the total Unified Parkinson's Disease Rating Scale score of PD [31]. Early clinical trials revealed that hydrogen improves PD through antioxidation. More recent research found that hydrogen may slightly increase oxidative stress or act as the rectifier of the mitochondrial electron flow and improve PD by regulating mitochondrial energy [24] or via hormetic mechanisms. By hormetic mechanisms, $\mathrm{H}_{2}$ will simulate strenuous exercise to generate a mild increase of ROS which will evoke hormesis and then activate the Nrf2, NF- $\kappa \mathrm{B}$ pathways, and heat shock responses to protect neurons and other tissues [16]. Hydrogen also improved cognitive function in Alzheimer's patients in a clinical trial [79]. The collective findings indicate the safety and effectiveness of hydrogen in the treatment of neurodegenerative diseases.

Hydrogen has also been shown to protect the nervous system of a fetus or newborn. In two case studies, pregnant women who had become infected with COVID-19 displayed a high delivery rate of fetuses with intrauterine distress leading to a higher incidence of perinatal hypoxic-ischemic brain damage $[77,78]$. The findings indicate the necessity of measures to prevent neonatal encephalopathy or reduce neonatal neurological deficit for pregnant women infected with COVID-19. $\mathrm{H}_{2}$ can inhibit the activation of proinflammatory cytokines, microglia [79], and 8-hydroxy dehydrogenase (8OHdG) $[80]$ to reduce oxidative damage and neuroinflam- mation in the fetal brain in animal models. The protective effects have been verified by clinical trials. Hippocampal damage caused by I/R injury in the uterus on day 7 after birth was reportedly improved for pregnant women who had been treated with HW and was associated with reductions of 4hydroxy ketone and 8-OHdG [81]. The available data support the possibility that hydrogen therapy could protect fetuses of pregnant women infected with COVID-19. In addition, hydrogen can also protect against spinal cord injury and a variety of brain injuries caused by ischemia, hypoxia, trauma, and hemorrhage. A clinical study of patients suffering from cerebral infarction reported that hydrogen inhalation improved imaging results, National Institutes of Health Stroke Scale scores used to quantify the severity of stroke, and physical therapy evaluations based on the Barthel Index [82]. A rat model of subarachnoid hemorrhage revealed the influence of hydrogen in lessening neurological deficits [83] and endothelial cell injury [84]. In rats, hydrogen can also relieve neuropathic pain [85] after spinal cord injury and can ameliorate neurotoxicity [69].

3.3. Effects of Hydrogen on Cardiovascular Diseases. With the acceleration of urbanization and aging of global societies, the risk of cardiovascular diseases (CVD) has increased. The World Health Organization ranks CVD as the leading cause 
of death globally, accounting for 17.5 million deaths annually. Two of every five deaths in China are attributed to CVD, which exceeds the death rate due to cancer or other diseases [86]. However, most clinical trials to date have failed to effectively prevent and treat CVD. Thus, novel therapies are urgently required.

During the past decade, many basic and clinical studies have provided evidence supporting the view that $\mathrm{H}_{2}$ treatment protects against CVD and improves cardiac function. Ohsawa et al. discovered that consumption of HW for 6 months reduced the oxidative stress level and the volume of atherosclerotic lesions derived from macrophage accumulation in apolipoprotein E knockout mice (ApoE-/- mice) [87]. Iketani et al. recently revealed that continuous administration of HW in low-density lipoprotein (LDL) receptordeficient mice decreased the numbers of endothelial cells in the atheroma expressing the senescence factors p16INK4a and $\mathrm{p} 21$, as well as suppressing macrophage infiltration and TNF- $\alpha$ expression in the atheroma, suggesting that vascular aging can be suppressed by HW [88]. Another study demonstrated increased flow-mediated dilation in the high- $\mathrm{H}_{2}$ group in which eight males and females drank HW containing $7 \mathrm{ppm} \mathrm{H}_{2}$, indicating that $\mathrm{H}_{2}$ may protect the vasculature from shear stress-derived ROS that is detrimental [89].

In addition to treating atherosclerosis, $\mathrm{H}_{2}$ reduces MIRI, which refers to a heart lesion that develops upon the resumption of the flow of oxygen-rich blood after a period of ischemia and which usually occurs during acute myocardial infarction or open-heart surgery $[40,90]$. A recent series of studies by Li et al. found that HW inhibited cardiomyocyte apoptosis by activating the PI3K/AKT and JAK2-STAT3 signaling pathways and can also reduce the level of oxidative stress in myocardial tissue by upregulating the expression of the nuclear erythroid 2-related factor 2/antioxidant response element (Nrf2/ARE) signaling pathway, which alleviated I/R injury in isolated rat hearts $[39,40,91]$. Other studies demonstrated that intraperitoneal injection of HW before reperfusion significantly decreased the concentration of malondialdehyde (MDA) and infarct size, as well as reducing myocardial 8OHdG and the levels of TNF- $\alpha$ and IL- $1 \beta$ in an area at risk zones [92, 93]. Moreover, Qian et al. described the hydrogen-mediated protection of myocardium degeneration due to radiation-induced injury in rats [94]. Treatment with HRS was shown to ameliorate vascular dysfunction, including aortic hypertrophy and endothelial function, in spontaneously hypertensive rats by abating oxidative stress, restoring baroreflex function, preserving mitochondrial function, and enhancing nitric oxide bioavailability [95]. In another study, the intraperitoneal administration of HRS improved hemodynamics and reversed right ventricular hypertrophy in male Sprague-Dawley rats with pulmonary hypertension induced by monocrotaline [96]. $\mathrm{H}_{2}$ inhalation is also a favorable strategy to mitigate mortality and functional outcome of postcardiac arrest syndrome in a rat model [97]. These collective findings indicate the potential of $\mathrm{H}_{2}$ in novel therapeutic approaches for the clinical treatment of CVD.

3.4. Effects of Hydrogen on Digestive System Diseases. Hepatic ischemia-reperfusion injury (HIRI) is common in liver sur- gery and liver transplantation. $\mathrm{H}_{2}$ treatment ameliorated HIRI in a mouse fatty liver model by reducing hepatocyte apoptosis, inhibiting macrophage activation and inflammatory cytokines, and inducing HO-1 and Sirtl expression [98]. Inhalation of high concentrations of hydrogen significantly improved liver function in a mouse HIRI model by activating the A2A receptor-mediated PI3K-Akt pathway [99]. A recent series of studies also discovered that portal vein injection of HRS in miniature pigs with laparoscopic HIRI promoted liver function recovery and liver regeneration by reducing hepatocyte autophagy and apoptosis and inhibited ER stress, with significant hepatoprotective effects observed [100-103]. Hydrogen flush after cold storage refers to an end-ischemic $\mathrm{H}_{2}$ flush directly to donor organs ex vivo. This approach can significantly protect liver grafts from IRI [104], providing a potentially effective strategy for organ preservation. Other studies demonstrated the protective effects of $\mathrm{H}_{2}$ in liver damage induced by parasites [105], obstructive jaundice [106], shock and resuscitation [107], sepsis [108], doxorubicin [6], and aflatoxin B1 [109]. In a mouse model of nonalcoholic fatty liver disease (NAFLD), HW downregulated Nrf2-mediated miR-136 expression by targeting the maternally expressed 3 long noncoding RNA gene [110], providing a rationale for further clinical trials. In a human study, HW also significantly reduced liver fat accumulation in twelve overweight outpatients with NAFLD [111]. Another in vivo study revealed that oral HW significantly attenuated oxidative stress in patients with chronic hepatitis B [112]. In recent years, it has become widely accepted that bile acids are a nutrient signaling hormone [113]. Molecular hydrogen was recently demonstrated to participate in the regulation of bile acid metabolism, particularly in the inhibition of bile acid oxidation, in some gut bacteria [114].

Intestinal $\mathrm{I} / \mathrm{R}$ injury is a multifactorial pathophysiological process with high morbidity and mortality. I/R injury occurs in a variety of clinical settings that include major cardiovascular surgery, trauma, shock, and small intestinal transplantation [115]. Yao et al. recently observed that intraperitoneal injection of $\mathrm{H}_{2}$ attenuated I/R-induced mucosal injury and apoptosis of epithelial cells in mice by regulating miRNAs, in particular by regulating miR-199a-3p [116]. Furthermore, HW reportedly inhibited intestinal I/R-induced oxidative stress, apoptosis, and inflammation and promoted epithelial cell proliferation in rats, which protected against intestinal contractile dysfunction and damage induced by intestinal I/R [117-119]. Most gastrointestinal microbial species encode the genetic capacity to metabolize $\mathrm{H}_{2}$, meaning that $\mathrm{H}_{2}$ might affect the gut bacterial composition [120], and bacterial translocation is an important cause of multiple organ dysfunction syndromes in critical illness. Ikeda et al. described that the luminal administration of HW prevented intestinal dysbiosis, hyperpermeability, and bacterial translocation in a murine model of sepsis [121]. In another study, the inhalation of $2 \% \mathrm{H}_{2}$ also attenuated intestinal injuries caused by severe sepsis in male Nrf2 $\mathrm{KO}$ mice by regulating HO- 1 and HMGB1 release [122]. Moreover, an in vivo study revealed that $\mathrm{H}_{2}$ inhalation improved the prognosis in patients with stage IV colorectal cancer by activating PGC$1 \alpha$ and restoring exhausted CD8+ T cells [123]. 
Wang et al. interestingly discovered that cytotoxinassociated gene A cytotoxin, a virulence factor of Helicobacter pylori that augments the risk of gastric cancer, can be delivered into host cells by the $\mathrm{H}_{2}$-utilizing respiratory chain of the bacterium, extending the roles of $\mathrm{H}_{2}$ oxidation to include transport of a carcinogenic toxin [124]. Although this study indicated that $\mathrm{H}_{2}$ may play a role in increasing gastric cancer risk, abundant studies also demonstrated that $\mathrm{H}_{2}$ is protective in gastric damage induced by oxidative stress [125] and aspirin [126]. Franceschelli et al. found that electrolyzed reduced water, which is rich in molecular hydrogen, rapidly improved symptoms in patients with gastroesophageal reflux disease [127]. $\mathrm{H}_{2}$ treatment also controlled the severity of chronic pancreatitis [15] and acute necrotizing pancreatitis [128].

3.5. Effects of Hydrogen on Reproductive System Diseases. Yang et al. recently demonstrated using a mouse model of human endometrial tumor xenograft that HW has an antitumor effect that was sufficient to inhibit xenograft volume and weight of endometrial tumors via the ROS/NLRP3/caspase-1/GSDMD-mediated pyroptotic pathway, indicating a biphasic effect of $\mathrm{H}_{2}$ on cancer that involves the promotion of tumor cell death and protection of normal cells [129]. Other authors reported that $\mathrm{H}_{2}$ inhalation reduced the size of the endometrial explants, inhibited cell proliferation, improved $\mathrm{SOD}$, and regulated the expression of matrix metalloproteinase 9 and cyclooxygenase 2 in an endometriosis rat model [130]. HRS is effective in attenuating ovary injury induced by I/R [131] and cisplatin [132]. HW improved serum antiMüllerian hormone levels and reduced ovarian granulosa cell apoptosis in a mouse immune premature ovarian failure model induced by zona pellucida glycoprotein 3 [133]. In a hemisectioned spinal cord injury rat model, HRS inhibited the injury-induced ultrastructural changes in gonadotrophs, ameliorated the abnormal regulation of the hypothalamicpituitary-testis axis, and thereby promoted the recovery of testicular injury [134]. In irradiated rats, HRS improved testis weight, testis dimensions, sperm count, sperm motility, and serum testosterone levels [135]. HW stimulated spermatogenesis as well as increased sperm production and sperm motility in mice of different ages [136]. Based on previous studies, Begum et al. hypothesized that $\mathrm{H}_{2}$ may modulate intracellular MAPK cAMP and $\mathrm{Ca}^{2+}$ signals involved in testosterone hormone production to improve male fertility caused by redox imbalance [137]. Finally, $\mathrm{H}_{2}$ decreased the percentage of sperm abnormalities and improved sperm morphology following the prolonged exposure of mouse low doses of radiation [138]. The collective data indicate that hydrogen can protect both female and male fertility.

3.6. Effects of Hydrogen on Urinary System Diseases. Acute kidney injury (AKI) is an important risk factor for the development of chronic kidney disease. Wu et al. recently found that saturated hydrogen alleviates CCL4-induced AKI via JAK2/STAT3/p65 signaling [139]. Inhalation of a hydrogen-rich aerosol appears to be very useful for renal protection and inflammation reduction in septic AKI, based on the observations of increased anti-inflammatory cytokine (IL-4 and IL-13) mRNA levels in renal tissues and increased macrophage polarization to the M2 type, which generates additional anti-inflammatory cytokines (IL-10 and transforming growth factor-beta, TGF- $\beta$ ) [140]. Additionally, $\mathrm{H}_{2}$ can alleviate AKI induced by I/R [141], liver transplantation [142], burns [143], and sodium taurocholate-induced acute pancreatitis [144]. Recently, Lu et al. demonstrated that HW can restore a balanced redox status and alleviate cyclosporine A-induced nephrotoxicity by activating the Keap1/Nrf2 signaling pathway [145]. $\mathrm{H}_{2}$ can ameliorate kidney injury induced by chronic intermittent hypoxia by decreasing ER stress and activating autophagy through the inhibition of oxidative stress-dependent p38 and JNK MAPK activation [46]. HW also reportedly can inhibit the development of renal fibrosis and prevent HK-2 cells from undergoing EMT mediated through Sirt1, a downstream molecule of TGF- $\beta 1$. HRS markedly reduced interstitial congestion, edema, and hemorrhage in renal tissue, prevented renal injury, and promoted renal function recovery after $\mathrm{I} / \mathrm{R}$ injury in rats through antiapoptotic and antiinflammatory actions in kidney cells [146]. Other authors described that HW significantly reduced the increased postvoid residual volume in obstructed rats and ameliorated bladder dysfunction secondary to bladder outlet obstruction by attenuating oxidative stress [147].

3.7. Effects of Hydrogen on Metabolic Syndrome. Metabolic syndrome is associated with excess calorie intake and encompasses a range of medical conditions that include obesity, insulin resistance, and dyslipidemia. Many studies have demonstrated the protective effects of $\mathrm{H}_{2}$ in metabolic syndrome. Qiu et al. reported that saturated hydrogen decreased total cholesterol, total glyceride, and LDL, increased highdensity lipoprotein in the peripheral blood, and alleviated the activity of isocitratelyase, suggesting that $\mathrm{H}_{2}$ could improve lipid metabolism disorders by inhibiting the glyoxylic acid cycle [148]. Glucose and insulin levels in the serum were also significantly lower in $\mathrm{H}_{2}$-treated mice, which markedly improved type 2 diabetes mellitus and diabetic nephropathy-related outcomes [149]. Moreover, gut-derived hydrogen production induced by L-arabinose reportedly had beneficial effects on metabolic syndrome in C57BL/6J mice fed a high-fat diet [150] and reduced oxidative stress and the peripheral blood IL-1 $\beta$ mRNA level in sixteen type 2 diabetic patients [151]. $\mathrm{H}_{2}$ treatment has also shown positive effects on energy metabolism. In 2011, Kamimura et al. reported that prolonged consumption of HW significantly controlled fat and body weights in $\mathrm{db} / \mathrm{db}$ obese mice by stimulating energy metabolism [152]. A recent study revealed that $\mathrm{H}_{2}$ attenuated allergic inflammation in a mouse model of allergic airway inflammation by reversing an energy metabolic pathway switch from oxidative phosphorylation to aerobic glycolysis [153].

3.8. Effects of Hydrogen on Motor System Diseases. Although many studies have investigated the effectiveness of $\mathrm{H}_{2}$ on various diseases related to oxidative stress, little is known about the influence of $\mathrm{H}_{2}$ on exercise-induced oxidative stress. In 2012, Aoki et al. found that HW reduced blood lactate levels and improved exercise-induced decline of muscle function in ten male soccer players [47]. Yamazaki et al. discovered that 
the serum 8-OHdG levels in $\mathrm{H}_{2}$-treated race horses were significantly suppressed, strongly suggesting a protective effect of $\mathrm{H}_{2}$ in exercise-induced, ROS-mediated detrimental tissue damage [154]. Additionally, hydrogen bathing attenuated exercise-induced muscle damage and delayed-onset muscle soreness but had no effects on the peripheral neutrophil count and both dynamics and functions of neutrophils [155]. These findings highlight that further studies are needed to clarify the mechanisms of $\mathrm{H}_{2}$. Inhalation of $\mathrm{H}_{2}$ significantly decreased infarct zone and area with loss of tissue structure, attenuated muscle damage, and enhanced functional recovery in a mouse hindlimb $\mathrm{I} / \mathrm{R}$ injury model [156]. Finally, Hasegawa et al. revealed that $\mathrm{H}_{2}$ improved muscular dystrophy in the mdx mouse model for Duchenne muscular dystrophy [157].

3.9. Effects of Hydrogen on Sensory System Diseases. Hydrogen has a therapeutic role in alleviating the damage to some sensory organs, mainly through antioxidation. Hydrogen promotes wound healing in tissue or protective barriers including skin and mucosa. For example, preinhalation of hydrogen-containing gas decreased wound healing time in a rat model of radiation-induced skin injury [158]. Other authors reported that $\mathrm{H}_{2}$ inhalation reduced the wound area and levels of proinflammatory cytokines in pressure ulcers [159]. Moreover, hydrogen can improve skin lesions in some immune disorders by interfering with the immune system or ROS removal [160]. HW also benefits the wound healing process of the oral palate. Hydrogen also may protect hearing and vision. Kurioka et al. [161] demonstrated that hydrogen inhalation significantly reduced outer hair cell loss and improved auditory brainstem response after noise exposure, indicating a protective effect for noise-induced hearing loss. Hydrogen has been shown to be effective in treating cornea injury caused by alkali [162], fluoride, chloropicrin [163], and ultraviolet $B$ radiation [164].

3.10. Effects of Hydrogen on Cancer. Many animal models have established the efficacy of hydrogen against cancers. The attributes of hydrogen include blocking of the regulator for chromosome condensation [43], some crucial molecules in stemness [165], proliferation [123], and angiogenesis [165], and the alleviation of oxidative stress. The combination therapy of hydrogen and other novel antineoplastic drugs, such as LY294002 [166], which is an inhibitor of PI3K, has demonstrated great potential and efficacy. An increasing number of clinical trials are being carried out. A recent survey [140] on 82 advanced cancer patients exemplified that hydrogen can control cancer progression and improve the quality-of-life. Akagi [37] treated 55 stage IV colorectal carcinoma patients using hydrogen inhalation and documented enhanced mitochondrial activity due to the activation of PGC- $1 \alpha$ to reduce the proportion of terminal PD-1+ CD8+ T cells. The depletion of these cells is associated with improved cancer prognosis [37, 123]. This therapeutic effect has also been confirmed in another trial conducted in one patient with metastatic gallbladder cancer [167]. In a case report in 2019, hydrogen gas therapy resulted in 1the disappearance of the metastatic brain tumors in a woman diagnosed with lung cancer [168]. Finally, hydrogen can also reduce the side effects of cisplatin [169] and radiotherapy [170]. Though growing evidences have shown the effects of $\mathrm{H} 2$ on alleviating both cancer progression and side effects of chemotherapeutics, the $\mathrm{H} 2$ therapy applied in cancer is just in a nascent stage. At present, the published researches on the anticancer effects of $\mathrm{H} 2$ mainly focus on lung cancer [168], colorectal cancer [37], and glioma [165]. It remains unclear how many cancers can effectively be alleviated by $\mathrm{H}_{2}$ and how many can not be.

At present, patients with COVID-19 pneumonia are usually treated with high flow pure oxygen (without adding $\mathrm{H}_{2}$ ), although the effect of $\mathrm{O}_{2}$ when associated with $\mathrm{H}_{2}$ may give better results [171]. The production of mucus in these patients reduces the absorption of $\mathrm{O}_{2}$, while with a mixture of $\mathrm{O}_{2}$ and $\mathrm{H}_{2}$, the bronchioles and the alveoli of lungs are further expanded, optimizing the absorption of $\mathrm{O}_{2}$ [172]. $\mathrm{H}_{2}$ is used as a catalyst to accelerate the binding of hemoglobin with $\mathrm{O}_{2}$ and the release of hemoglobin with carbon dioxide [173].

\section{Conclusions}

Hydrogen has great potential in the regulation of oxidative stress, inflammation, energy metabolism of organelles, and programmed cell death. Many animal experiments and clinical trials have established the protective effects of hydrogen on many organs and systems.

Research in this area has increased over the past 15 years. However, the details of the specific molecular mechanisms of the therapeutic effects of hydrogen remain unclear. For example, whether hydrogen can truly be used to regulate ferroptosis, pyroptosis, or the circadian clock is not known. Since $\mathrm{H}_{2}$ is not something like rapamycin or leucine only going to have one direction (opposite) effects on autophagy, is it possible to regulate autophagy or apoptosis in a specific direction? Previous studies have clearly explained the antioxidative stress effect of hydrogen. However, some recent clinical trials have shown that $\mathrm{H}_{2}$ can induce oxidative stress in some cases as well. Ventilation with $\mathrm{H}_{2}$ can induce a mild increase of ROS to activate the Nrf2, NF- $\kappa \mathrm{B}$ pathways, and heat shock responses. $\mathrm{H}_{2}$-induced ROS production can also be observed in cancer cells. The specific mechanism underlying the hydrogen-induced increase of oxidative stress should be explained by more experiments. These and other questions concerning the mechanism of hydrogen should be further explored.

There are many factors that limit the clinical use of hydrogen. Firstly, hydrogen is considered unsafe at concentrations above $4 \%$ because such a high level of $\mathrm{H}_{2}$ is explosive and might bring cytotoxic effects. Previous studies have indicated that the concentration of hydrogen should be stabilized beyond $2 \%$ to enable protection from acute oxidative stress. However, even $2 \%$ of hydrogen is not absolutely safe. Most clinical ventilators are equipped with platinum hot manometers, because $\mathrm{H}_{2}$ and $\mathrm{O}_{2}$ can overheat the platinum surface at room temperature. Secondly, there is a lack of specialized devices that enable the administration of effective hydrogen concentrations, while ensuring that they are safe. Thirdly, 
there have been few large-scale controlled human studies on the effects of hydrogen. Fourthly, Liu and his colleagues demonstrated that the inhalation of $\mathrm{H}_{2}$ resulted in a slower elevation of the $\mathrm{H}_{2}$ concentration than that achieved with intraperitoneal, intravenous, or oral administration. However, the elevated $\mathrm{H}_{2}$ concentrations were maintained for at least 60 minutes after inhalation. Thus, it should be deliberated to choose the administration of $\mathrm{H}_{2}$ [7]. As a result, the dose-specific effects or side effects of hydrogen in humans remain unclear.

The data regarding the known mechanisms underlying the action of hydrogen indicate that hydrogen can alleviate the damage in multiple organs in NCP patients. The comparisons of the different modalities of hydrogen indicate the value of $\mathrm{HW}$ in the effective treatment of such patients.

Hydrogen is inexpensive and safe and can be administered through many ways. We anticipate that as large-scale clinical trials confirm the therapeutic efficacy and safety of hydrogen, its full clinical potential will be realized.

\section{Abbreviation}

$\begin{array}{ll}\text { NCP: } & \text { Novel coronavirus pneumonia } \\ \mathrm{H}_{2}: & \text { Hydrogen } \\ \text { I/R: } & \text { Ischemia/reperfusion } \\ \text { HRS: } & \mathrm{H}_{2} \text {-rich saline } \\ \mathrm{HW}: & \mathrm{H}_{2} \text {-rich water } \\ \text { ROS: } & \text { Reactive oxygen species } \\ \text { ER: } & \text { Endoplasmic reticulum } \\ \text { EMT: } & \text { Epithelial-mesenchymal transition } \\ \text { CVD: } & \text { Cardiovascular diseases } \\ \text { NAFLD: } & \text { Nonalcoholic fatty liver disease } \\ \text { AKI: } & \text { Acute kidney injury } \\ \text { MDA: } & \text { Malondialdehyde } \\ \text { Nrf2: } & \text { Nuclear erythroid 2-related factor } 2 \\ \text { PGC-1 } \alpha: & \text { Peroxisome proliferator-activated receptor- } \\ & \text { gamma coactivator-1 alpha. }\end{array}$

\section{Conflicts of Interest}

The authors declare no conflict of interest.

\section{Authors' Contributions}

Mengling Yang and Yinmiao Dong collected the literature and drafted the initial manuscript. Yinmiao Dong, Jie Shen, and Xueyan Zhang assisted in the preparation of the figures and table. Qingnan He, Quan Zhuang, and Ping Zhu revised the manuscript and edited the language. Mingyi Zhao was the lead investigator. All authors approved the final manuscript as submitted and are accountable for all aspects of the work. Mengling Yang, Yinmiao Dong, and Qingnan He contributed equally to this article.

\section{Acknowledgments.}

This research was funded by the National Key Research and Development Program of China (2018YFA0108700 and 2017YFA0105602), the NSFC Projects of International
Cooperation and Exchanges (81720108004), the National Natural Science Foundation of China (81570279, 81974019, and 81970248), the Research Team Project of Natural Science Foundation of Guangdong Province of China (2017A030312007), the key program of Guangzhou science research plan (805212639211), and the Special Project of Dengfeng Program of Guangdong Provincial People's Hospital (DFJH201812 and KJ012019119).

\section{References}

[1] J. H. Abraini, M. C. Gardette-Chauffour, E. Martinez, J. C. Rostain, and C. Lemaire, "Psychophysiological reactions in humans during an open sea dive to $500 \mathrm{~m}$ with a hydrogenhelium-oxygen mixture," Journal of Applied Physiology, vol. 76, no. 3, pp. 1113-1118, 1994.

[2] M. Dole, F. Wilson, and W. Fife, "Hyperbaric hydrogen therapy: a possible treatment for cancer," Science, vol. 190, no. 4210, pp. 152-154, 1975.

[3] I. Ohsawa, M. Ishikawa, K. Takahashi et al., "Hydrogen acts as a therapeutic antioxidant by selectively reducing cytotoxic oxygen radicals," Nature Medicine, vol. 13, no. 6, pp. 688694, 2007.

[4] M. Chen, J. Zhang, Y. Chen et al., "Hydrogen protects lung from hypoxia/re-oxygenation injury by reducing hydroxyl radical production and inhibiting inflammatory responses," Scientific Reports, vol. 8, no. 1, p. 8004, 2018.

[5] Y. Bi, Y. Zhu, M. Zhang et al., "Effect of shikonin on spinal cord injury in rats via regulation of HMGB1/TLR4/NF-kB signaling pathway," Cellular Physiology and Biochemistry, vol. 43, no. 2, pp. 481-491, 2017.

[6] Y. Gao, H. Yang, Y. Fan, L. Li, J. Fang, and W. Yang, "Hydrogen-rich saline attenuates cardiac and hepatic injury in doxorubicin rat model by inhibiting inflammation and apoptosis," Mediators of Inflammation, vol. 2016, Article ID 1320365, 10 pages, 2016.

[7] C. Liu, R. Kurokawa, M. Fujino, S. Hirano, B. Sato, and X. K. $\mathrm{Li}$, "Estimation of the hydrogen concentration in rat tissue using an airtight tube following the administration of hydrogen via various routes," Scientific Reports, vol. 4, no. 1, article 5485, 2015.

[8] W. Liu, L. P. Shan, X. S. Dong, X. W. Liu, T. Ma, and Z. Liu, "Combined early fluid resuscitation and hydrogen inhalation attenuates lung and intestine injury," World Journal of Gastroenterology, vol. 19, no. 4, pp. 492-502, 2013.

[9] Y. Yu, Y. Yang, M. Yang, C. Wang, K. Xie, and Y. Yu, "Hydrogen gas reduces HMGB1 release in lung tissues of septic mice in an Nrf2/HO-1-dependent pathway," International Immunopharmacology, vol. 69, pp. 11-18, 2019.

[10] Y. Tanaka, N. Shigemura, T. Kawamura et al., "Profiling molecular changes induced by hydrogen treatment of lung allografts prior to procurement," Biochemical and Biophysical Research Communications, vol. 425, no. 4, pp. 873-879, 2012.

[11] C. S. Huang, T. Kawamura, S. Lee et al., "Hydrogen inhalation ameliorates ventilator-induced lung injury," Critical Care, vol. 14, no. 6, article R234, 2010.

[12] A. Manaenko, T. Lekic, Q. Ma, J. H. Zhang, and J. Tang, "Hydrogen inhalation ameliorated mast cell-mediated brain injury after intracerebral hemorrhage in mice," Critical Care Medicine, vol. 41, no. 5, pp. 1266-1275, 2013. 
[13] D. Schmit, D. D. le, S. Heck et al., "Allergic airway inflammation induces migration of mast cell populations into the mouse airway," Cell and Tissue Research, vol. 369, no. 2, pp. 331-340, 2017.

[14] T. Kajisa, T. Yamaguchi, A. Hu, N. Suetake, and H. Kobayashi, "Hydrogen water ameliorates the severity of atopic dermatitis-like lesions and decreases interleukin$1 \beta$, interleukin-33, and mast cell infiltration in $\mathrm{NC} / \mathrm{Nga}$ mice," Saudi Medical Journal, vol. 38, no. 9, pp. 928-933, 2017.

[15] L. Chen, C. Ma, Y. Bian et al., "Hydrogen treatment protects mice against chronic pancreatitis by restoring regulatory $\mathrm{T}$ cells loss," Cellular Physiology and Biochemistry, vol. 44, no. 5, pp. 2005-2016, 2017.

[16] M. Hirayama, M. Ito, T. Minato, A. Yoritaka, T. W. LeBaron, and K. Ohno, "Inhalation of hydrogen gas elevates urinary 8hydroxy-2'-deoxyguanine in Parkinson's disease," Medical Gas Research, vol. 8, no. 4, pp. 144-149, 2018.

[17] S. Liu, K. Liu, Q. Sun et al., "Consumption of hydrogen water reduces paraquat-induced acute lung injury in rats," Journal of Biomedicine \& Biotechnology, vol. 2011, Article ID 305086, 7 pages, 2011.

[18] Y.-S. Zhao, J. R. An, S. Yang et al., "Hydrogen and oxygen mixture to improve cardiac dysfunction and myocardial pathological changes induced by intermittent hypoxia in rats," Oxidative Medicine and Cellular Longevity, vol. 2019, Article ID 7415212, 12 pages, 2019.

[19] K. Ohno, M. Ito, M. Ichihara, and M. Ito, "Molecular hydrogen as an emerging therapeutic medical gas for neurodegenerative and other diseases," Oxidative Medicine and Cellular Longevity, vol. 2012, Article ID 353152, 11 pages, 2012.

[20] M. Ichihara, S. Sobue, M. Ito, M. Ito, M. Hirayama, and K. Ohno, "Beneficial biological effects and the underlying mechanisms of molecular hydrogen - comprehensive review of 321 original articles," Medical Gas Research, vol. 5, no. 1, p. 12, 2015.

[21] K. Iuchi, K. Nishimaki, N. Kamimura, and S. Ohta, "Molecular hydrogen suppresses free-radical-induced cell death by mitigating fatty acid peroxidation and mitochondrial dysfunction," Canadian Journal of Physiology and Pharmacology, vol. 97, no. 10, pp. 999-1005, 2019.

[22] K. Kohama, H. Yamashita, M. Aoyama-Ishikawa et al., "Hydrogen inhalation protects against acute lung injury induced by hemorrhagic shock and resuscitation," Surgery, vol. 158, no. 2, pp. 399-407, 2015.

[23] M. Diao, S. Zhang, L. Wu et al., "Hydrogen gas inhalation attenuates seawater instillation-induced acute lung injury via the Nrf2 pathway in rabbits," Inflammation, vol. 39, no. 6, pp. 2029-2039, 2016.

[24] T. Ishibashi, "Therapeutic efficacy of molecular hydrogen: a new mechanistic insight," Current Pharmaceutical Design, vol. 25, no. 9, pp. 946-955, 2019.

[25] Y. Gao, H. Yang, J. Chi et al., "Hydrogen gas attenuates myocardial ischemia reperfusion injury independent of postconditioning in rats by attenuating endoplasmic reticulum stress-induced autophagy," Cellular Physiology and Biochemistry, vol. 43, no. 4, pp. 1503-1514, 2017.

[26] H. Zhong, R. Song, Q. Pang et al., "Propofol inhibits parthanatos via ROS-ER-calcium-mitochondria signal pathway in vivo and vitro," Cell Death \& Disease, vol. 9, no. 10, pp. 932-932, 2018.
[27] X. Chen, J. Cui, X. Zhai et al., "Inhalation of hydrogen of different concentrations ameliorates spinal cord injury in mice by protecting spinal cord neurons from apoptosis, oxidative injury and mitochondrial structure damages," Cellular Physiology and Biochemistry, vol. 47, no. 1, pp. 176-190, 2018.

[28] Q. Li, P. Yu, Q. Zeng et al., "Neuroprotective effect of hydrogen-rich saline in global cerebral ischemia/reperfusion rats: up-regulated Tregs and down-regulated miR-21, miR-210 and NF- $\kappa \mathrm{B}$ expression," Neurochemical Research, vol. 41, no. 10, pp. 2655-2665, 2016.

[29] X. Ma, J. Wang, J. Li et al., "Loading MiR-210 in endothelial progenitor cells derived exosomes boosts their beneficial effects on hypoxia/reoxygeneation-injured human endothelial cells via protecting mitochondrial function," Cellular Physiology and Biochemistry, vol. 46, no. 2, pp. 664-675, 2018.

[30] R. K. Mutharasan, V. Nagpal, Y. Ichikawa, and H. Ardehali, "MicroRNA-210 is upregulated in hypoxic cardiomyocytes through Akt- and p53-dependent pathways and exerts cytoprotective effects," Heart and Circulatory Physiology, vol. 301, no. 4, pp. H1519-H1530, 2011.

[31] A. Yoritaka, M. Takanashi, M. Hirayama, T. Nakahara, S. Ohta, and N. Hattori, "Pilot study of $\mathrm{H}_{2}$ therapy in Parkinson's disease: a randomized double-blind placebo-controlled trial," Movement Disorders, vol. 28, no. 6, pp. 836-839, 2013.

[32] Y. Murakami, M. Ito, and I. Ohsawa, "Molecular hydrogen protects against oxidative stress-induced SH-SY5Y neuroblastoma cell death through the process of mitohormesis," PLoS One, vol. 12, no. 5, article e0176992, 2017.

[33] J. Meng, P. Yu, H. Jiang et al., "Molecular hydrogen decelerates rheumatoid arthritis progression through inhibition of oxidative stress," American Journal of Translational Research, vol. 8, no. 10, pp. 4472-4477, 2016.

[34] T. Ishibashi, "Molecular hydrogen: new antioxidant and antiinflammatory therapy for rheumatoid arthritis and related diseases," Current Pharmaceutical Design, vol. 19, no. 35, pp. 6375-6381, 2013.

[35] M. Ito, T. Ibi, K. Sahashi, M. Ichihara, M. Ito, and K. Ohno, "Open-label trial and randomized, double-blind, placebocontrolled, crossover trial of hydrogen-enriched water for mitochondrial and inflammatory myopathies," Medical Gas Research, vol. 1, no. 1, p. 24, 2011.

[36] Q. Zhu, Y. Wu, Y. Li et al., "Positive effects of hydrogen-water bathing in patients of psoriasis and parapsoriasis en plaques," Scientific Reports, vol. 8, no. 1, pp. 8051-8051, 2018.

[37] F. Xu, S. Yu, M. Qin et al., "Hydrogen-rich saline ameliorates allergic rhinitis by reversing the imbalance of Th1/Th2 and up-regulation of CD4+CD25+Foxp3+regulatory $\mathrm{T}$ cells, interleukin-10, and membrane-bound transforming growth factor- $\beta$ in guinea pigs," Inflammation, vol. 41, no. 1, pp. 81-92, 2018.

[38] J. Akagi, "Immunological effect of hydrogen gas-hydrogen gas improves clinical outcomes of cancer patients," Gan to Kagaku Ryoho, vol. 45, no. 10, pp. 1475-1478, 2018.

[39] Y. Terasaki, I. Ohsawa, M. Terasaki et al., "Hydrogen therapy attenuates irradiation-induced lung damage by reducing oxidative stress," American Journal of Physiology Lung Cellular and Molecular Physiology, vol. 301, no. 4, pp. L415L426, 2011.

[40] L. Li, X. Li, Z. Zhang et al., "Effects of hydrogen-rich water on the PI3K/AKT signaling pathway in rats with myocardial 
ischemia-reperfusion injury," Current Molecular Medicine, vol. 20, no. 5, pp. 396-406, 2020.

[41] X. Li, L. Li, X. Liu et al., "Attenuation of cardiac ischaemiareperfusion injury by treatment with hydrogen-rich water," Current Molecular Medicine, vol. 19, no. 4, pp. 294-302, 2019.

[42] Y. Zhang, Y. Liu, and J. Zhang, "Saturated hydrogen saline attenuates endotoxin-induced lung dysfunction," The Journal of Surgical Research, vol. 198, no. 1, pp. 41-49, 2015.

[43] D. Li and Y. Ai, "Hydrogen saline suppresses neuronal cell apoptosis and inhibits the p38 mitogen-activated protein kinase-caspase-3 signaling pathway following cerebral ischemia-reperfusion injury," Molecular Medicine Reports, vol. 16, no. 4, pp. 5321-5325, 2017.

[44] D. Wang, L. Wang, Y. Zhang, Y. Zhao, and G. Chen, "Hydrogen gas inhibits lung cancer progression through targeting SMC3," Biomedicine \& Pharmacotherapy, vol. 104, pp. 788797, 2018.

[45] Q. Li, Y. Tanaka, and N. Miwa, "Influence of hydrogenoccluding-silica on migration and apoptosis in human esophageal cells in vitro," Medical Gas Research, vol. 7, no. 2, pp. 76-85, 2017.

[46] X. Zhuang, Y. Yu, Y. Jiang et al., "Molecular hydrogen attenuates sepsis-induced neuroinflammation through regulation of microglia polarization through an mTOR-autophagydependent pathway," International Immunopharmacology, vol. 81, article 106287, 2020.

[47] P. Guan, Z. M. Sun, L. F. Luo et al., "Hydrogen protects against chronic intermittent hypoxia induced renal dysfunction by promoting autophagy and alleviating apoptosis," Life Sciences, vol. 225, pp. 46-54, 2019.

[48] J. Yuan, D. Wang, Y. Liu, X. Chen, and H. Zhang, "Effects of hydrogen rich water on the expression of $\mathrm{Nrf} 2$ and the oxidative stress in rats with traumatic brain injury," Zhonghua wei zhong bing ji jiu yi xue, vol. 27, no. 11, pp. 911-915, 2015.

[49] A. Pla, M. Pascual, J. Renau-Piqueras, and C. Guerri, “TLR4 mediates the impairment of ubiquitin-proteasome and autophagy-lysosome pathways induced by ethanol treatment in brain," Cell Death \& Disease, vol. 5, no. 2, article e1066, 2014.

[50] S. M. Man, R. Karki, and T.-D. Kanneganti, "Molecular mechanisms and functions of pyroptosis, inflammatory caspases and inflammasomes in infectious diseases," Immunological Reviews, vol. 277, no. 1, pp. 61-75, 2017.

[51] M. Yan, Y. Yu, X. Mao et al., "Hydrogen gas inhalation attenuates sepsis-induced liver injury in a FUNDC1-dependent manner," International Immunopharmacology, vol. 71, pp. 61-67, 2019.

[52] S. Tan, Z. Long, $X$. Hou et al., " $H_{2}$ protects against lipopolysaccharide-induced cardiac dysfunction via blocking TLR4mediated cytokines expression," Frontiers in Pharmacology, vol. 10, pp. 865-865, 2019.

[53] Q. Pu, C. Gan, R. Li et al., "Atg7 deficiency intensifies inflammasome activation and pyroptosis in Pseudomonas Sepsis," Journal of immunology, vol. 198, no. 8, pp. 3205-3213, 2017.

[54] M. Deng, Y. Tang, W. Li et al., "The endotoxin delivery protein HMGB1 mediates caspase-11-dependent lethality in sepsis," Immunity, vol. 49, no. 4, pp. 740-753.e7, 2018.

[55] C. Li, L. Hou, D. Chen et al., "Hydrogen-rich saline attenuates isoflurane-induced caspase-3 activation and cognitive impairment via inhibition of isoflurane-induced oxidative stress, mitochondrial dysfunction, and reduction in ATP levels," American Journal of Translational Research, vol. 9, no. 3, pp. 1162-1172, 2017.

[56] C. Y. Taabazuing, M. C. Okondo, and D. A. Bachovchin, "Pyroptosis and apoptosis pathways engage in bidirectional crosstalk in monocytes and macrophages," Cell chemical biology, vol. 24, no. 4, pp. 507-514.e4, 2017.

[57] S. J. Dixon, K. M. Lemberg, M. R. Lamprecht et al., "Ferroptosis: an iron-dependent form of nonapoptotic cell death," Cell, vol. 149, no. 5, pp. 1060-1072, 2012.

[58] Y. Li, F. Chen, J. Chen et al., "Disulfiram/copper induces antitumor activity against both nasopharyngeal cancer cells and cancer-associated fibroblasts through ROS/MAPK and ferroptosis pathways," Cancers, vol. 12, no. 1, p. 138, 2020.

[59] F. Ye, W. Chai, M. Xie et al., "HMGB1 regulates erastininduced ferroptosis via RAS-JNK/p38 signaling in HL60/NRAS ${ }^{\text {Q61L }}$ cells," American Journal of Cancer Research, vol. 9, no. 4, pp. 730-739, 2019.

[60] O. Adedoyin, R. Boddu, A. Traylor et al., "Heme oxygenase-1 mitigates ferroptosis in renal proximal tubule cells," Renal Physiology, vol. 314, no. 5, pp. F702-F714, 2018.

[61] C. Li, X. Deng, X. Xie, Y. Liu, J. P. Friedmann Angeli, and L. Lai, "Activation of glutathione peroxidase 4 as a novel anti-inflammatory strategy," Frontiers in Pharmacology, vol. 9, pp. 1120-1120, 2018.

[62] F. A.-O. X. Rijo-Ferreira and J. S. Takahashi, "Genomics of circadian rhythms in health and disease," Genome Medicine, vol. 11, no. 1, p. 82, 2019.

[63] C. A. Thaiss, M. Levy, T. Korem et al., "Microbiota diurnal rhythmicity programs host transcriptome oscillations," Cell, vol. 167, no. 6, pp. 1495-1510.e12, 2016.

[64] A. Iida, N. Nosaka, T. Yumoto et al., "The clinical application of hydrogen as a medical treatment," Acta Medica Okayama, vol. 70, no. 5, pp. 331-337, 2016.

[65] M. Wilking, M. Ndiaye, H. Mukhtar, and N. Ahmad, "Circadian rhythm connections to oxidative stress: implications for human health," Antioxidants \& Redox Signaling, vol. 19, no. 2, pp. 192-208, 2013.

[66] G. Russell, M. Rehman, L. B. TW, D. Veal, E. Adukwu, and J. Hancock, "An overview of SARS-CoV-2 (COVID-19) infection and the importance of molecular hydrogen as an adjunctive therapy," Reactive Oxygen Specieshttps://uwerepository.worktribe.com/output/6050001.

[67] W.-J. Guan, C. H. Wei, A. L. Chen et al., "Hydrogen/oxygen mixed gas inhalation improves disease severity and dyspnea in patients with Coronavirus disease 2019 in a recent multicenter, open-label clinical trial," Journal of Thoracic Disease, vol. 12, no. 6, pp. 3448-3452, 2020.

[68] F. Zhou, T. Yu, R. du et al., "Clinical course and risk factors for mortality of adult inpatients with COVID-19 in Wuhan, China: a retrospective cohort study," The Lancet, vol. 395, no. 10229, pp. 1054-1062, 2020.

[69] C. Huang, Y. Wang, X. Li et al., "Clinical features of patients infected with 2019 novel coronavirus in Wuhan, China," The Lancet, vol. 395, no. 10223, pp. 497-506, 2020.

[70] L. Gattinoni, T. Tonetti, and M. Quintel, "Regional physiology of ARDS," Critical Care, vol. 21, Supplement 3, p. 312, 2017.

[71] W. W. Dong, Y. Q. Zhang, X. Y. Zhu et al., "Protective effects of hydrogen-rich saline against lipopolysaccharide-induced alveolar epithelial-to-mesenchymal transition and pulmonary fibrosis," Medical Science Monitor, vol. 23, pp. 2357-2364, 2017. 
[72] T. Wang, L. Zhao, M. Liu et al., "Oral intake of hydrogen-rich water ameliorated chlorpyrifos-induced neurotoxicity in rats," Toxicology and Applied Pharmacology, vol. 280, no. 1, pp. 169-176, 2014.

[73] Y. Liu and J. Zhang, "Saturated hydrogen saline ameliorates lipopolysaccharide-induced acute lung injury by reducing excessive autophagy," Experimental and Therapeutic Medicine, vol. 13, no. 6, pp. 2609-2615, 2017.

[74] X. Chen, Q. Liu, D. Wang et al., "Protective effects of hydrogen-rich saline on rats with smoke inhalation injury," Oxidative Medicine and Cellular Longevity, vol. 2015, Article ID 106836, 8 pages, 2015.

[75] D. H. Moon, D. Y. Kang, S. J. Haam et al., "Hydrogen gas inhalation ameliorates lung injury after hemorrhagic shock and resuscitation," Journal of Thoracic Disease, vol. 11, no. 4, pp. 1519-1527, 2019.

[76] Z. Liu, W. Geng, C. Jiang et al., "Hydrogen-rich saline inhibits tobacco smoke-induced chronic obstructive pulmonary disease by alleviating airway inflammation and mucus hypersecretion in rats," Experimental Biology and Medicine, vol. 242, no. 15, pp. 1534-1541, 2017.

[77] Y. Fu, M. Ito, Y. Fujita et al., "Molecular hydrogen is protective against 6-hydroxydopamine-induced nigrostriatal degeneration in a rat model of Parkinson's disease," Neuroscience Letters, vol. 453, no. 2, pp. 81-85, 2009.

[78] K. Fujita, T. Seike, N. Yutsudo et al., "Hydrogen in drinking water reduces dopaminergic neuronal loss in the 1-methyl4-phenyl-1,2,3,6-tetrahydropyridine mouse model of Parkinson's disease," PLoS One, vol. 4, no. 9, p. e7247, 2009.

[79] K. Nishimaki, T. Asada, I. Ohsawa et al., "Effects of molecular hydrogen assessed by an animal model and a randomized clinical study on mild cognitive impairment," Current Alzheimer Research, vol. 15, no. 5, pp. 482-492, 2018.

[80] H. Chen, J. Guo, C. Wang et al., "Clinical characteristics and intrauterine vertical transmission potential of COVID-19 infection in nine pregnant women: a retrospective review of medical records," The Lancet, vol. 395, no. 10226, pp. 809$815,2020$.

[81] H. Zhu, L. Wang, C. Fang et al., "Clinical analysis of 10 neonates born to mothers with 2019-nCoV pneumonia," Translational Pediatrics, vol. 9, no. 1, pp. 51-60, 2020.

[82] K. Imai, T. Kotani, H. Tsuda et al., "Administration of molecular hydrogen during pregnancy improves behavioral abnormalities of offspring in a maternal immune activation model," Scientific Reports, vol. 8, no. 1, article 9221, 2018.

[83] J. Nemeth, V. Toth-Szuki, V. Varga, V. Kovacs, G. Remzso, and F. Domoki, "Molecular hydrogen affords neuroprotection in a translational piglet model of hypoxic-ischemic encephalopathy," Journal of Physiology and Pharmacology, vol. 67, no. 5, pp. 677-689, 2016.

[84] Y. Mano, T. Kotani, M. Ito et al., "Maternal molecular hydrogen administration ameliorates rat fetal hippocampal damage caused by in utero ischemia-reperfusion," Free Radical Biology and Medicine, vol. 69, pp. 324-330, 2014.

[85] H. Ono, Y. Nishijima, S. Ohta et al., "Hydrogen gas inhalation treatment in acute cerebral infarction: a randomized controlled clinical study on safety and neuroprotection," Journal of Stroke and Cerebrovascular Diseases, vol. 26, no. 11, pp. 2587-2594, 2017.

[86] R. Camara, N. Matei, J. Camara, B. Enkhjargal, J. Tang, and J. H. Zhang, "Hydrogen gas therapy improves survival rate and neurological deficits in subarachnoid hemorrhage rats: a pilot study," Medical Gas Research, vol. 9, no. 2, pp. 74-79, 2019.

[87] K. Zhuang, Y. C. Zuo, P. Sherchan, J. K. Wang, X. X. Yan, and F. Liu, "Hydrogen inhalation attenuates oxidative stress related endothelial cells injury after subarachnoid hemorrhage in rats," Frontiers in Neuroscience, vol. 13, article 1441, 2020.

[88] H. Chen, C. Zhou, K. Xie, X. Meng, Y. Wang, and Y. Yu, "Hydrogen-rich saline alleviated the hyperpathia and microglia activation via autophagy mediated inflammasome inactivation in neuropathic pain rats," Neuroscience, vol. 421, pp. 17-30, 2019.

[89] L. Y. Ma, W. W. Chen, R. L. Gao et al., "China cardiovascular diseases report 2018: an updated summary," Journal of Geriatric Cardiology, vol. 17, no. 1, pp. 1-8, 2020.

[90] I. Ohsawa, K. Nishimaki, K. Yamagata, M. Ishikawa, and S. Ohta, "Consumption of hydrogen water prevents atherosclerosis in apolipoprotein E knockout mice," Biochemical and Biophysical Research Communications, vol. 377, no. 4, pp. 1195-1198, 2008.

[91] M. Iketani, K. Sekimoto, T. Igarashi et al., "Administration of hydrogen-rich water prevents vascular aging of the aorta in LDL receptor-deficient mice," Scientific Reports, vol. 8, no. 1, article 16822, 2018.

[92] T. Sakai, B. Sato, K. Hara et al., "Consumption of water containing over $3.5 \mathrm{mg}$ of dissolved hydrogen could improve vascular endothelial function," Vascular Health and Risk Management, vol. 10, pp. 591-597, 2014.

[93] J. Ding, Z. Yang, H. Ma, and H. Zhang, "Mitochondrial aldehyde dehydrogenase in myocardial ischemic and ischemiareperfusion injury," in Aldehyde Dehydrogenases, vol. 1193 of Advances in Experimental Medicine and Biology, Springer, Singapore.

[94] L. Li, T. Liu, L. Liu et al., "Effect of hydrogen-rich water on the Nrf2/ARE signaling pathway in rats with myocardial ischemia-reperfusion injury," Journal of Bioenergetics and Biomembranes, vol. 51, no. 6, pp. 393-402, 2019.

[95] Y. Zhang, Q. Sun, B. He, J. Xiao, Z. Wang, and X. Sun, “Antiinflammatory effect of hydrogen-rich saline in a rat model of regional myocardial ischemia and reperfusion," International Journal of Cardiology, vol. 48, no. 1, pp. 91-95, 2011.

[96] Q. Sun, Z. Kang, J. Cai et al., "Hydrogen-rich saline protects myocardium against ischemia/reperfusion injury in rats," Experimental Biology and Medicine, vol. 234, no. 10, pp. 1212-1219, 2009.

[97] L. Qian, F. Cao, J. Cui et al., "The potential cardioprotective effects of hydrogen in irradiated mice," Journal of Radiation Research, vol. 51, no. 6, pp. 741-747, 2010.

[98] H. Zheng and Y. S. Yu, "Chronic hydrogen-rich saline treatment attenuates vascular dysfunction in spontaneous hypertensive rats," Biochemical Pharmacology, vol. 83, no. 9, pp. 1269-1277, 2012.

[99] Y. Wang, L. Jing, X. M. Zhao et al., "Protective effects of hydrogen-rich saline on monocrotaline-induced pulmonary hypertension in a rat model," Respiratory Research, vol. 12, no. $1,2011$.

[100] K. Hayashida, M. Sano, N. Kamimura et al., "H2Gas improves functional outcome after cardiac arrest to an extent comparable to therapeutic hypothermia in a rat model," Journal of the American Heart Association, vol. 1, no. 5, article e003459, 2012. 
[101] Y. Ding, H. Wang, H. Shen et al., "The clinical pathology of severe acute respiratory syndrome (SARS): a report from China," The Journal of Pathology, vol. 200, no. 3, pp. 282289, 2003.

[102] A. Badawi and S. G. Ryoo, "Prevalence of comorbidities in the Middle East respiratory syndrome coronavirus (MERSCoV): a systematic review and meta-analysis," International Journal of Infectious Diseases, vol. 49, pp. 129-133, 2016.

[103] K. J. Clerkin, J. A. Fried, J. Raikhelkar et al., "COVID-19 and Cardiovascular Disease," Circulation, vol. 141, no. 20, pp. 1648-1655, 2020.

[104] E. Driggin, M. V. Madhavan, B. Bikdeli et al., "Cardiovascular Considerations for Patients, Health Care Workers, and Health Systems During the COVID-19 Pandemic," Journal of the American College of Cardiology, vol. 75, no. 18, pp. 2352-2371, 2020.

[105] B. Li, J. Yang, F. Zhao et al., "Prevalence and impact of cardiovascular metabolic diseases on COVID-19 in China," Clinical Research in Cardiology, vol. 109, no. 5, pp. 531-538, 2020.

[106] S. Li, M. Fujino, N. Ichimaru et al., "Molecular hydrogen protects against ischemia-reperfusion injury in a mouse fatty liver model via regulating HO-1 and Sirtl expression," Scientific Reports, vol. 8, no. 1, article 14019, 2018.

[107] H. Li, O. Chen, Z. Ye et al., "Inhalation of high concentrations of hydrogen ameliorates liver ischemia/reperfusion injury through A $2 \mathrm{~A}$ receptor mediated PI3K-Akt pathway," Biochemical Pharmacology, vol. 130, no. 83, pp. 83-92, 2017.

[108] Q. Zhang, C. Piao, J. Xu et al., "Comparative study on protective effect of hydrogen rich saline and adipose- derived stem cells on hepatic ischemia-reperfusion and hepatectomy injury in swine," Biomedicine \& Pharmacotherapy, vol. 120, article 109453, 2019.

[109] Q. Zhang, Y. Ge, H. Li et al., "Corrigendum to "Effect of hydrogen-rich saline on apoptosis induced by hepatic ischemia reperfusion upon laparoscopic hepatectomy in miniature pigs" [Research in Veterinary Science, Volume 119, August 2018, Pages 285-291]," Research in Veterinary Science, vol. 126, p. 37, 2019.

[110] G. Bai, H. Li, Y. Ge et al., "Influence of hydrogen-rich saline on hepatocyte autophagy during laparoscopic liver ischaemia-reperfusion combined resection injury in miniature pigs," Journal of Veterinary Research, vol. 62, no. 3, pp. 395-403, 2018.

[111] H. Li, G. Bai, Y. Ge et al., "Hydrogen-rich saline protects against small-scale liver ischemia-reperfusion injury by inhibiting endoplasmic reticulum stress," Life Sciences, vol. 194, pp. 7-14, 2018.

[112] I. Tamaki, K. Hata, Y. Okamura et al., "Hydrogen flush after cold storage as a new end-ischemic ex vivo treatment for liver grafts against ischemia/reperfusion injury," Liver Transplantation, vol. 24, no. 11, pp. 1589-1602, 2018.

[113] B. Gharib, S. Hanna, O. M. S. Abdallahi, H. Lepidi, B. Gardette, and M. de Reggi, "Anti-inflammatory properties of molecular hydrogen: investigation on parasite- induced liver inflammation," Comptes Rendus de l'Académie des Sciences - Series III - Sciences de la Vie, vol. 324, no. 8, pp. 719-724, 2001.

[114] Q. Liu, W. F. Shen, H. Y. Sun et al., "Hydrogen-rich saline protects against liver injury in rats with obstructive jaundice," Liver International, vol. 30, no. 7, pp. 958-968, 2010.
[115] Y. Dang, T. Liu, X. Mei et al., "Hyperoxygenated hydrogenrich solution suppresses shock- and resuscitation- induced liver injury," Journal of Surgical Research, vol. 220, pp. 363-371, 2017.

[116] M. Iketani, J. Ohshiro, T. Urushibara et al., "Preadministration of hydrogen-rich water protects against lipopolysaccharide-induced sepsis and attenuates liver injury," Shock, vol. 48, no. 1, pp. 85-93, 2017.

[117] H. L. Hu, J. Gao, W. J. Guo, F. H. Zhou, H. Y. Liu, and C. C. $\mathrm{Su}$, "Anti-injury effect of hydrogen-enriched water in a rat model of liver injury induced by aflatoxin $\mathrm{B}_{1}$," Acta Physiologica Sinica, vol. 71, no. 5, pp. 725-731, 2019.

[118] X. Wang and J. Wang, "High-content hydrogen waterinduced downregulation of miR-136 alleviates non-alcoholic fatty liver disease by regulating Nrf2 via targeting MEG3," Biological Chemistry, vol. 399, no. 4, pp. 397406, 2018.

[119] D. Korovljev, V. Stajer, J. Ostojic, T. W. LeBaron, and S. M. Ostojic, "Hydrogen-rich water reduces liver fat accumulation and improves liver enzyme profiles in patients with non-alcoholic fatty liver disease: a randomized controlled pilot trial," Clinics and Research in Hepatology and Gastroenterology, vol. 43, no. 6, pp. 688-693, 2019.

[120] C. Xia, W. Liu, D. Zeng, L. Zhu, X. Sun, and X. Sun, "Effect of hydrogen-rich water on oxidative stress, liver function, and viral load in patients with chronic hepatitis B," Clinical and Translational Science, vol. 6, no. 5, pp. 372-375, 2013.

[121] T. Li and J. Y. L. Chiang, "Bile acid signaling in metabolic disease and drug therapy," Pharmacological Reviews, vol. 66, no. 4, pp. 948-983, 2014.

[122] S. C. Harris, S. Devendran, C. Méndez-García et al., "Bile acid oxidation by Eggerthella lenta strains C592 and DSM 2243"," Gut Microbes, vol. 9, no. 6, pp. 523-539, 2018.

[123] K. Katada, T. Takagi, K. Uchiyama, and Y. Naito, “Therapeutic roles of carbon monoxide in intestinal ischemia-reperfusion injury," Journal of Gastroenterology and Hepatology, vol. 30, pp. 46-52, 2015.

[124] W. Yao, X. Lin, X. Han et al., "MicroRNA files in the prevention of intestinal ischemia/reperfusion injury by hydrogen rich saline," Bioscience Reports, vol. 40, no. 1, 2020.

[125] H. Chen, Y. P. Sun, P. F. Hu et al., "The effects of hydrogenrich saline on the contractile and structural changes of intestine induced by ischemia-reperfusion in rats," Journal of Surgical Research, vol. 167, no. 2, pp. 316-322, 2011.

[126] T. Shigeta, S. Sakamoto, X. K. Li et al., "Luminal injection of hydrogen-rich solution attenuates intestinal ischemia-reperfusion injury in rats," Transplantation, vol. 99, no. 3, pp. 500-507, 2015.

[127] S. Eryilmaz, Z. Turkyilmaz, R. Karabulut et al., "The effects of hydrogen-rich saline solution on intestinal anastomosis performed after intestinal ischemia reperfusion injury," Journal of Pediatric Surgery, 2020.

[128] Y. Higashimura, Y. Baba, R. Inoue et al., "Effects of molecular hydrogen-dissolved alkaline electrolyzed water on intestinal environment in mice," Medical Gas Research, vol. 8, no. 1, pp. 6-11, 2018.

[129] M. Ikeda, K. Shimizu, H. Ogura et al., "Hydrogen-rich saline regulates intestinal barrier dysfunction, dysbiosis, and bacterial translocation in a murine model of sepsis," Shock, vol. 50, no. 6, pp. 640-647, 2018.

[130] Y. Yu, Y. Yang, Y. Bian et al., "Hydrogen gas protects against intestinal injury in wild type but not NRF2 knockout mice 
with severe sepsis by regulating HO-1 and HMGB1 release," Shock, vol. 48, no. 3, pp. 364-370, 2017.

[131] J. Akagi and H. Baba, "Hydrogen gas restores exhausted CD8 $+\mathrm{T}$ cells in patients with advanced colorectal cancer to improve prognosis," Oncology Reports, vol. 41, no. 1, pp. 301-311, 2019.

[132] G. Wang, J. Romero-Gallo, S. L. Benoit et al., "Hydrogen metabolism inHelicobacter pyloriPlays a role in gastric carcinogenesis through facilitating CagA translocation," mBio, vol. 7 , no. 4, 2016 .

[133] X. Liu, Z. Chen, N. Mao, and Y. Xie, "The protective of hydrogen on stress-induced gastric ulceration," International Immunopharmacology, vol. 13, no. 2, pp. 197-203, 2012.

[134] J.-Y. Zhang, Q. F. Wu, Y. Wan et al., "Protective role of hydrogen-rich water on aspirin-induced gastric mucosal damage in rats," World Journal of Gastroenterology, vol. 20, no. 6, pp. 1614-1622, 2014.

[135] S. Franceschelli, D. M. P. Gatta, M. Pesce et al., "Modulation of the oxidative plasmatic state in gastroesophageal reflux disease with the addition of rich water molecular hydrogen: a new biological vision," Journal of Cellular and Molecular Medicine, vol. 22, no. 5, pp. 2750-2759, 2018.

[136] Q. Shi, C. Chen, W. H. Deng et al., "Hydrogen-rich saline attenuates acute hepatic injury in acute necrotizing pancreatitis by inhibiting inflammation and apoptosis, involving JNK and p38 mitogen-activated protein kinase-dependent reactive oxygen species," Pancreas, vol. 45, no. 10, pp. 1424-1431, 2016.

[137] Y. Yang, P. Y. Liu, W. Bao, S. J. Chen, F. S. Wu, and P. Y. Zhu, "Hydrogen inhibits endometrial cancer growth via a ROS/NLRP3/caspase-1/GSDMD-mediated pyroptotic pathway," BMC Cancer, vol. 20, no. 1, p. 28, 2020.

[138] Y. He, J. Z. Shi, R. J. Zhang et al., "Effects of hydrogen gas inhalation on endometriosis in rats," Reproductive Sciences, vol. 24, no. 2, pp. 324-331, 2016.

[139] N. Gokalp, A. C. Basaklar, K. Sonmez et al., "Protective effect of hydrogen rich saline solution on experimental ovarian ischemia reperfusion model in rats," Journal of Pediatric Surgery, vol. 52, no. 3, pp. 492-497, 2017.

[140] X. Meng, H. Chen, G. Wang, Y. Yu, and K. Xie, "Hydrogenrich saline attenuates chemotherapy-induced ovarian injury via regulation of oxidative stress," Experimental and Therapeutic Medicine, vol. 10, no. 6, pp. 2277-2282, 2015.

[141] X. He, S. Y. Wang, C. H. Yin, T. Wang, C. W. Jia, and Y. M. $\mathrm{Ma}$, "Hydrogen-rich water exerting a protective effect on ovarian reserve function in a mouse model of immune premature ovarian failure induced by zona pellucida 3," Chinese Medical Journal, vol. 129, no. 19, pp. 2331-2337, 2016.

[142] L. Ge, L. H. Wei, C. Q. du et al., "Hydrogen-rich saline attenuates spinal cord hemisection-induced testicular injury in rats," Oncotarget, vol. 8, no. 26, pp. 42314-42331, 2017.

[143] Z. Jiang, B. Xu, M. Yang, Z. Li, Y. Zhang, and D. Jiang, "Protection by hydrogen against gamma ray-induced testicular damage in rats," Basic \& Clinical Pharmacology \& Toxicology, vol. 112, no. 3, pp. 186-191, 2013.

[144] J. Y. Ku, M. J. Park, H. J. Park, N. C. Park, and B. S. Joo, "Combination of Korean red ginseng extract and hydrogenrich water improves spermatogenesis and sperm motility in male mice," Chinese Journal of Integrative Medicine, vol. 26, no. 5, pp. 361-369, 2020.
[145] R. Begum, J. Bajgai, A. Fadriquela, C. S. Kim, S. K. Kim, and K. J. Lee, "Molecular hydrogen may enhance the production of testosterone hormone in male infertility through hormone signal modulation and redox balance," Medical Hypotheses, vol. 121, pp. 6-9, 2018.

[146] J. Guo, D. Zhao, X. Lei et al., "Protective effects of hydrogen against low-dose long-term radiation-induced damage to the behavioral performances, hematopoietic system, genital system, and splenic lymphocytes in mice," Oxidative Medicine and Cellular Longevity, vol. 2016, Article ID 1947819, 15 pages, 2016.

[147] S. Wu, Z. Fang, and S. Zhou, "Saturated hydrogen alleviates CCl4-induced acute kidney injury via JAK2/STAT3/p65 signaling," The Journal of International Medical Research, vol. 48, no. 1, 2020.

[148] W. Yao, A. Guo, X. Han et al., "Aerosol inhalation of a hydrogen-rich solution restored septic renal function," Aging, vol. 11, no. 24, pp. 12097-12113, 2019.

[149] J. Chen, H. Zhang, J. Hu et al., "Hydrogen-rich saline alleviates kidney fibrosis following AKI and retains klotho expression," Frontiers in Pharmacology, vol. 8, p. 499, 2017.

[150] H. Du, M. Sheng, L. Wu et al., "Hydrogen-rich saline attenuates acute kidney injury after liver transplantation via activating p53-mediated autophagy," Transplantation, vol. 100, no. 3, pp. 563-570, 2016.

[151] S. X. Guo, Q. Fang, C. G. You et al., "Effects of hydrogen-rich saline on early acute kidney injury in severely burned rats by suppressing oxidative stress induced apoptosis and inflammation," Journal of Translational Medicine, vol. 13, no. 1, p. 183, 2015.

[152] Q. Shi, K. S. Liao, K. L. Zhao et al., "Hydrogen-Rich Saline Attenuates Acute Renal Injury in Sodium TaurocholateInduced Severe Acute Pancreatitis by Inhibiting ROS and NF- $\kappa$ B Pathway," Mediators of Inflammation, vol. 2015, Article ID 685043, 13 pages, 2015.

[153] Y. Lu, C.-. F. Li, N.-. N. Ping et al., "Hydrogen-rich water alleviates cyclosporine $\mathrm{A}$-induced nephrotoxicity via the Keap1/Nrf2 signaling pathway," Journal of Biochemical and Molecular Toxicology, vol. 34, no. 5, article e22467, 2020.

[154] Z. Xing, W. Pan, J. Zhang et al., "Hydrogen rich water attenuates renal injury and fibrosis by regulation transforming growth factor- $\beta$ induced Sirt1," Biological \& Pharmaceutical Bulletin, vol. 40, no. 5, pp. 610-615, 2017.

[155] J. Li, Z. Hong, H. Liu et al., "Hydrogen-rich saline promotes the recovery of renal function after ischemia/reperfusion injury in rats via anti-apoptosis and anti-inflammation," Frontiers in Pharmacology, vol. 7, p. 106, 2016.

[156] N. Miyazaki, O. Yamaguchi, M. Nomiya, K. Aikawa, and J. Kimura, "Preventive effect of hydrogen water on the development of detrusor overactivity in a rat model of bladder outlet obstruction," The Journal of Urology, vol. 195, no. 3, pp. 780-787, 2016.

[157] X. Qiu, Q. Ye, M. Sun, L. Wang, Y. Tan, and G. Wu, "Saturated hydrogen improves lipid metabolism disorders and dysbacteriosis induced by a high-fat diet," Experimental Biology and Medicine, vol. 245, no. 6, pp. 512-521, 2020.

[158] X. Zhang, J. Liu, K. Jin et al., "Subcutaneous injection of hydrogen gas is a novel effective treatment for type 2 diabetes," Journal of Diabetes Investigation, vol. 9, no. 1, pp. 8390, 2018.

[159] L. Zhao, Y. Wang, G. Zhang, T. Zhang, J. Lou, and J. Liu, "LArabinose elicits gut-derived hydrogen production and 
ameliorates metabolic syndrome in C57BL/6J mice on highfat-diet," Nutrients, vol. 11, no. 12, p. 3054, 2019.

[160] A. Tamasawa, K. Mochizuki, N. Hariya et al., "Hydrogen gas production is associated with reduced interleukin- $1 \beta$ mRNA in peripheral blood after a single dose of acarbose in Japanese type 2 diabetic patients," European Journal of Pharmacology, vol. 762, pp. 96-101, 2015.

[161] N. Kamimura, K. Nishimaki, I. Ohsawa, and S. Ohta, "Molecular hydrogen improves obesity and diabetes by inducing hepatic FGF21 and stimulating energy metabolism in db/db mice," Obesity, vol. 19, no. 7, pp. 1396-1403, 2011.

[162] Y. Niu, Q. Nie, L. Dong et al., "Hydrogen attenuates allergic inflammation by reversing energy metabolic pathway switch," Scientific Reports, vol. 10, no. 1, article 1962, 2020.

[163] K. Aoki, A. Nakao, T. Adachi, Y. Matsui, and S. Miyakawa, "Pilot study: effects of drinking hydrogen-rich water on muscle fatigue caused by acute exercise in elite athletes," Medical Gas Research, vol. 2, no. 1, p. 12, 2012.

[164] M. Yamazaki, K. Kusano, T. Ishibashi, M. Kiuchi, and K. Koyama, "Intravenous infusion of H2-saline suppresses oxidative stress and elevates antioxidant potential in thoroughbred horses after racing exercise," Scientific Reports, vol. 5, no. 1, article 15514, 2015.

[165] T. Kawamura, K. Suzuki, M. Takahashi et al., "Involvement of neutrophil dynamics and function in exercise-induced muscle damage and delayed-onset muscle soreness: effect of hydrogen bath," Antioxidants, vol. 7, no. 10, p. 127, 2018.

[166] M. Watanabe, N. Kamimura, K. Iuchi et al., "Protective effect of hydrogen gas inhalation on muscular damage using a mouse hindlimb ischemia-reperfusion injury model," Plastic and Reconstructive Surgery, vol. 140, no. 6, pp. 1195-1206, 2017.

[167] S. Hasegawa, M. Ito, M. Fukami, M. Hashimoto, M. Hirayama, and K. Ohno, "Molecular hydrogen alleviates motor deficits and muscle degeneration in mdx mice," Redox Report, vol. 22, no. 1, pp. 26-34, 2016.

[168] S. Watanabe, M. Fujita, M. Ishihara et al., "Protective effect of inhalation of hydrogen gas on radiation-induced dermatitis and skin injury in rats," Journal of Radiation Research, vol. 55, no. 6, pp. 1107-1113, 2014.

[169] W. Fang, G. Wang, L. Tang et al., "Hydrogen gas inhalation protects against cutaneous ischaemia/reperfusion injury in a mouse model of pressure ulcer," Journal of Cellular and Molecular Medicine, vol. 22, no. 9, pp. 4243-4252, 2018.

[170] T. Ishibashi, M. Ichikawa, B. Sato et al., "Improvement of psoriasis-associated arthritis and skin lesions by treatment with molecular hydrogen: a report of three cases," Molecular Medicine Reports, vol. 12, no. 2, pp. 2757-2764, 2015.

[171] T. Kurioka, T. Matsunobu, Y. Satoh, K. Niwa, and A. Shiotani, "Inhaled hydrogen gas therapy for prevention of noise-induced hearing loss through reducing reactive oxygen species," Neuroscience Research, vol. 89, pp. 69-74, 2014.

[172] C. Cejka, J. Kossl, B. Hermankova, V. Holan, and J. Cejkova, "Molecular hydrogen effectively heals alkali-injured cornea via suppression of oxidative stress," Oxidative Medicine and Cellular Longevity, vol. 2017, Article ID 8906027, 12 pages, 2017.

[173] J. G. Lehman, R. D. Causey, C. V. LaGrasta, and A. L. Ruff, "High throughput siRNA screening for chloropicrin and hydrogen fluoride-induced cornea epithelial cell injury," Journal of Visualized Experiments, no. 136, 2018.

[174] C. Cejka, J. Kossl, B. Hermankova et al., “Therapeutic effect of molecular hydrogen in corneal UVB-induced oxidative stress and corneal photodamage," Scientific Reports, vol. 7, no. 1, article 18017, 2017.

[175] M. Y. Liu, F. Xie, Y. Zhang et al., "Molecular hydrogen suppresses glioblastoma growth via inducing the glioma stemlike cell differentiation," Stem Cell Research \& Therapy, vol. 10, no. 1, p. 145, 2019.

[176] Y. Jiang, G. Liu, L. Zhang et al., "Therapeutic efficacy of hydrogen-rich saline alone and in combination with PI3K inhibitor in non-small cell lung cancer," Molecular Medicine Reports, vol. 18, no. 2, pp. 2182-2190, 2018.

[177] J. Chen, F. Mu, T. Lu, Y. Ma, D. du, and K. Xu, "A gallbladder carcinoma patient with pseudo-progressive remission after hydrogen inhalation," OncoTargets and Therapy, vol. 12, pp. 8645-8651, 2019.

[178] J. Chen, F. Mu, T. Lu, D. du, and K. Xu, "Brain metastases completely disappear in non-small cell lung cancer using hydrogen gas inhalation: a case report," OncoTargets and Therapy, vol. 12, pp. 11145-11151, 2019.

[179] N. Nakashima-Kamimura, T. Mori, I. Ohsawa, S. Asoh, and S. Ohta, "Molecular hydrogen alleviates nephrotoxicity induced by an anti-cancer drug cisplatin without compromising anti-tumor activity in mice," Cancer Chemotherapy and Pharmacology, vol. 64, no. 4, pp. 753-761, 2009.

[180] K. Mei, S. Zhao, L. Qian, B. Li, J. Ni, and J. Cai, "Hydrogen protects rats from dermatitis caused by local radiation," The Journal of Dermatological Treatment, vol. 25, no. 2, pp. 182-188, 2013.

[181] Z. Xu, L. Shi, Y. Wang et al., "Pathological findings of COVID-19 associated with acute respiratory distress syndrome," The Lancet Respiratory Medicine, vol. 8, no. 4, pp. 420-422, 2020.

[182] W. J. Guan, R. C. Chen, and N. S. Zhong, "Strategies for the prevention and management of coronavirus disease 2019," European Respiratory Journal, vol. 55, no. 4, article 2000597, 2020. 